\title{
Fecal Microbiota Transplantation: A New Therapeutic Attempt from the Gut to the Brain
}

\author{
Hao-Ming Xu $\left(\mathbb{D}\right.$, Hong-Li Huang $\left(\mathbb{D}\right.$, You-Lian Zhou $\left(\mathbb{D}\right.$, Hai-Lan Zhao $\mathbb{D}^{D}$, Jing Xu $(\mathbb{D}$, \\ Di-Wen Shou $\mathbb{D}^{\text {D, }}$, Yan-Di Liu $\mathbb{D}$, Yong-Jian Zhou $\mathbb{D}^{\circ}$, and Yu-Qiang Nie
}

\begin{abstract}
Department of Gastroenterology and Hepatology, Guangzhou Digestive Disease Center, Guangzhou First People's Hospital, School of Medicine, South China University of Technology, Guangzhou 510180, China
\end{abstract}

Correspondence should be addressed to Yong-Jian Zhou; eyzhouyongjian@scut.edu.cn and Yu-Qiang Nie; eynieyuqiang@scut.edu.cn

Received 5 October 2020; Revised 26 November 2020; Accepted 5 January 2021; Published 16 January 2021

Academic Editor: Deng-Chyang Wu

Copyright ( 92021 Hao-Ming Xu et al. This is an open access article distributed under the Creative Commons Attribution License, which permits unrestricted use, distribution, and reproduction in any medium, provided the original work is properly cited.

Gut dysbacteriosis is closely related to various intestinal and extraintestinal diseases. Fecal microbiota transplantation (FMT) is a biological therapy that entails transferring the gut microbiota from healthy individuals to patients in order to reconstruct the intestinal microflora in the latter. It has been proved to be an effective treatment for recurrent Clostridium difficile infection. Studies show that the gut microbiota plays an important role in the pathophysiology of neurological and psychiatric disorders through the microbiota-gut-brain axis. Therefore, reconstruction of the healthy gut microbiota is a promising new strategy for treating cerebral diseases. We have reviewed the latest research on the role of gut microbiota in different nervous system diseases as well as FMT in the context of its application in neurological, psychiatric, and other nervous system-related diseases (Parkinson's disease, Alzheimer's disease, multiple sclerosis, epilepsy, autism spectrum disorder, bipolar disorder, hepatic encephalopathy, neuropathic pain, etc.).

\section{Introduction}

The gut microbiota is often considered an "invisible organ" that significantly affects human health and disease. More than 100 trillion microorganisms have been found in the human gastrointestinal (GI) tract, which encodes close to $3,000,0000$ genes compared to the 23,000 genes within the human genome $[1,2]$, and are crucial for maintaining the balance between different physiological activities. The cross-talk between the GI tract and the central nervous system, commonly known as the gut-brain axis, plays an important role in the pathophysiology of neurological diseases. Studies increasingly show that dysbacteriosis can lead to or exacerbate various neurological and psychiatric disorders, such as Parkinson's disease [3, 4], Alzheimer's disease [57], autism spectrum disorder [8], multiple sclerosis [9], and epilepsy [10]. In addition, patients with neurological dysfunction often present GI symptoms [11], which underscores the causative role of the gut in neuropathological progression and provides a solid rationale for therapeutically targeting the gut microbiota in these diseases (Table 1). The current therapies targeting the intestinal microbiota include the use of antibiotics, probiotics, prebiotics, synbiotics, and fecal microbiota transplantation (FMT) that entails transplanting functional microbiota from healthy individuals into the GI tracts of patients. FMT can reconstruct the healthy gut microecology and improve clinical symptoms. Apart from its direct therapeutic effect in GI diseases, FMT has also been shown to improve neurological and psychological symptoms by modulating the gut-brain axis (Figure 1) [12]. In this review, we have summarized the gut microbiota in different nervous system diseases as well as the current applications of FMT in various neurological and psychiatric diseases and discussed the potential mechanisms and future directions.

\section{Neurological Diseases}

Studies [46-48] show that the GI tract and resident microbiota are susceptible to the neurological dysfunction associated with Parkinson's disease, Alzheimer's disease, multiple 
TABLE 1: Characteristics, consequences, and application level of FMT in neuropsychological diseases.

\begin{tabular}{|c|c|c|c|c|}
\hline Disease types & Alterations of gut microbiota & $\begin{array}{l}\text { Altered substances caused by } \\
\text { microbial dysbiosis }\end{array}$ & $\begin{array}{l}\text { Application } \\
\text { level of } \\
\text { FMT }\end{array}$ & References \\
\hline \multicolumn{5}{|l|}{ Neurological diseases } \\
\hline Parkinson's disease & $\begin{array}{c}\text { Increase in Verrucomicrobiaceae, } \\
\text { Ruminococcaceae, Proteobacteria, Clostridiaceae, } \\
\text { Enterobacteriaceae, Bifidobacteriaceae, } \\
\text { Lactobacillaceae, Pasteurellaceae, } \\
\text { Christensenellaceae, Lactobacilli, Akkermansia, } \\
\text { Ralstonia } \\
\text { Decrease in Firmicutes, Prevotellaceae, } \\
\text { Coprococcus, Bacteroides fragilis, Blauti, } \\
\text { Roseburia, Faecalibacterium }\end{array}$ & $\begin{array}{l}\alpha \text {-Synuclein, LPS, SCFAs, } \\
\text { hydrogen production }\end{array}$ & $\begin{array}{l}\text { Patient \& } \\
\text { animal }\end{array}$ & {$[4,13,14]$} \\
\hline Alzheimer's disease & $\begin{array}{c}\text { Increase in Escherichia, Shigella, Chlamydia } \\
\text { pneumoniae, Borrelia burgdorferi, Treponema } \\
\text { pallidum, Burkholderiaceae, Staphylococcaceae, } \\
\text { Porphyromonas gingivalis, Propionibacterium } \\
\text { acnes } \\
\text { Decrease in Eubacterium rectale, Bacteroides } \\
\text { fragilis }\end{array}$ & $\begin{array}{l}\text { Inflammatory cytokines (IL-6, } \\
\text { CXCL2, NLRP3, IL-1 } \beta \text {, IL-10), } \\
\text { A } \beta, \text { GABA, BDNF, DHA }\end{array}$ & $\begin{array}{l}\text { Patient \& } \\
\text { animal }\end{array}$ & $\begin{array}{c}{[5,6,13} \\
15]\end{array}$ \\
\hline Multiple sclerosis & $\begin{array}{c}\text { Increase in Firmicutes, Clostridium, Escherichia } \\
\text { Shigella } \\
\text { Decrease in Bacteroides, Faecalibacterium, } \\
\text { Eubacterium rectale, Corynebacterium, } \\
\text { Fusobacteria }\end{array}$ & $\begin{array}{c}\text { Proinflammatory cytokines, } \\
\text { butyrate, lipid } 654\end{array}$ & $\begin{array}{l}\text { Patient \& } \\
\text { animal }\end{array}$ & {$[13]$} \\
\hline Epilepsy & $\begin{array}{c}\text { Increase in Firmicutes, Proteobacteria, } \\
\text { Clostridium, Cronobacter, Akkermansia, } \\
\text { Ruminococcus, Coprobacillus, Clostridium XVIII, } \\
\text { Atopobium, Holdemania, Dorea, } \\
\text { Saccharibacteria, Delftia, Paraprevotella, } \\
\text { Gemmiger, Neisseria, Coprococcus, } \\
\text { Fusobacterium, Methanobrevibacter, } \\
\text { Phascolarctobacterium, Roseburia } \\
\text { Decrease in Bacteroidetes, Actinobacteria, } \\
\text { Prevotella, Bifidobacterium }\end{array}$ & $\begin{array}{l}\text { Proinflammatory cytokines } \\
(\mathrm{TNF} \alpha, \mathrm{IL}-6, \mathrm{IL}-1 \beta) \\
\text { dopamine receptors } \mathrm{D} 1 \text { and } \\
\text { D2 }\end{array}$ & $\begin{array}{c}\text { Patient \& } \\
\text { animal }\end{array}$ & {$[16,17]$} \\
\hline Tourette Syndrome & $\begin{array}{l}\text { Increase in Bacteroidetes; in particular, } \\
\text { Bacteroides, Odoribacter, and Oscillospira were } \\
\text { identified as potential microbial biomarkers }\end{array}$ & $\begin{array}{l}\text { SCFAs, D-alanine, tyrosine, } \\
\text { dopamine }\end{array}$ & $\begin{array}{l}\text { Patient \& } \\
\text { animal }\end{array}$ & {$[18]$} \\
\hline $\begin{array}{l}\text { Myalgic } \\
\text { encephalomyelitis/chronic } \\
\text { fatigue syndrome }\end{array}$ & $\begin{array}{l}\text { Increase in Roseburia, Holdemania, } \\
\text { Enterococcus, Streptococcus spp. } \\
\text { Decrease in most Bacteroidetes genera. }\end{array}$ & $\begin{array}{l}\text { Lactic acid, LPS, LPS-binding } \\
\text { protein, soluble CD14, } \\
\text { oxidative stress }\end{array}$ & $\begin{array}{c}\text { Patient \& } \\
\text { animal }\end{array}$ & [19-21] \\
\hline Guillain-Barré Syndrome & $\begin{array}{c}\text { Campylobacter jejuni infection is associated with } \\
\text { GBS while Enterococcus faecalis as a potential } \\
\text { protective role }\end{array}$ & $\begin{array}{l}\text { LPS, peripheral nerve } \\
\text { gangliosides }\end{array}$ & Animal & {$[22,23]$} \\
\hline Stroke & $\begin{array}{l}\text { Decreased neuronal injury and improved } \\
\text { cognitive performance were observed in diabetic } \\
\text { mice with bilateral common carotid arteries } \\
\text { occlusion after receiving Clostridium butyricum }\end{array}$ & Trimethylamine $\mathrm{N}$-oxide & Animal & {$[24,25]$} \\
\hline $\begin{array}{l}\text { Amyotrophic lateral } \\
\text { sclerosis }\end{array}$ & $\begin{array}{c}\text { Increase in Dorea } \\
\text { Decrease in Butyrivibrio fibrisolvens, Firmicutes, } \\
\text { Peptostreptococcus, Escherichia coli, Oscillibacter, } \\
\text { Anaerostipes, Lachnospira }\end{array}$ & Butyrate & Animal & [26-28] \\
\hline Huntington's disease & $\begin{array}{c}\text { Increase in Bacteroidetes } \\
\text { Decrease in Firmicutes, Lachnospiraceae, } \\
\text { Akkermansiaceae }\end{array}$ & Methionine, glycine & Animal & {$[29,30]$} \\
\hline
\end{tabular}


TABLe 1: Continued.

\begin{tabular}{|c|c|c|c|c|}
\hline Disease types & Alterations of gut microbiota & $\begin{array}{l}\text { Altered substances caused by } \\
\text { microbial dysbiosis }\end{array}$ & $\begin{array}{l}\text { Application } \\
\text { level of } \\
\text { FMT }\end{array}$ & References \\
\hline \multicolumn{5}{|l|}{ Psychiatric diseases } \\
\hline Autism spectrum disorder & $\begin{array}{c}\text { Increase in Bacteroides, Barnesiella, Clostridium, } \\
\text { Roseburia } \\
\text { Decrease in Bifidobacterium, Coprococcus, } \\
\text { Dialister, Faecalibacterium, Prevotella, } \\
\text { Streptococcus }\end{array}$ & Butyrate, lactate & $\begin{array}{l}\text { Patient \& } \\
\text { animal }\end{array}$ & {$[31-33]$} \\
\hline Bipolar disorder & $\begin{array}{c}\text { Increase in Bacteroidetes, Actinobacteria, } \\
\text { Coriobacteria, Lachnospira, Enterobacteriaceae, } \\
\text { Flavonifractor } \\
\text { Decrease in Firmicutes, Ruminococcaceae, } \\
\text { Roseburia, Faecalibacterium, Coprococcus }\end{array}$ & Butyrate & $\begin{array}{l}\text { Patient \& } \\
\text { animal }\end{array}$ & {$[34-37]$} \\
\hline Depression & $\begin{array}{c}\text { Increase in Enterobacteriaceae, Prevotella, } \\
\text { Klebsiella, Alistipes } \\
\text { Decrease in Lachnospiraceae, Faecalibacterium, } \\
\text { Coprococcus, Dialister, Ruminococcus, } \\
\text { Lactobacillus, Bifidobacterium }\end{array}$ & $\begin{array}{l}\text { Butyrate, inflammatory } \\
\text { cytokines }\end{array}$ & $\begin{array}{l}\text { Patient \& } \\
\text { animal }\end{array}$ & $\begin{array}{l}{[36,38,} \\
39]\end{array}$ \\
\hline Anxiety & $\begin{array}{c}\text { Increase in Fusobacterium, Ruminococcus, } \\
\text { Escherichia Shigella } \\
\text { Decrease in Faecalibacterium, Eubacterium, } \\
\text { Sutterella }\end{array}$ & & Animal & {$[40,41]$} \\
\hline \multicolumn{5}{|c|}{ Other system-related neurological diseases } \\
\hline Hepatic encephalopathy & $\begin{array}{c}\text { Increases in Enterobacteriaceae, } \\
\text { Streptococcaceae, Porphyromonadaceae, } \\
\text { Staphylococcaceae, Enterococcaceae } \\
\text { Decrease in Lachnospiraceae, Ruminococcaceae, } \\
\text { Rikenellaceae, Clostridium XIV, } \\
\text { Phascolarctobacterium }\end{array}$ & $\begin{array}{l}\text { Ammonia, urease, SCFAs, } \\
\text { aromatic amino acids }\end{array}$ & $\begin{array}{l}\text { Patient \& } \\
\text { Animal }\end{array}$ & {$[42,43]$} \\
\hline Neuropathic pain & $\begin{array}{l}\text { Associated: Lactobacillus fermentum KBL374 \& } \\
\text { KBL375, Bacteroides fragilis, Escherichia coli, } \\
\text { Lactobacillus, Streptococcus spp., Enterococcus } \\
\text { spp., Corynebacterium glutamicum, } \\
\text { Peptostreptococcus, Clostridium sporogenes }\end{array}$ & $\begin{array}{l}\text { LPS, bacterial flagellin, indole, } \\
\text { SCFAs, PUFAs, BAs }\end{array}$ & $\begin{array}{l}\text { Patient \& } \\
\text { animal }\end{array}$ & {$[44]$} \\
\hline $\begin{array}{l}\text { Sepsis-associated } \\
\text { encephalopathy }\end{array}$ & $\begin{array}{c}\text { Associated: absence of anaerobes, including } \\
\text { Staphylococcus species and Escherichia coli, with } \\
\text { CDI, high relative abundance of pathogenic } \\
\text { gram negatives, and Enterococci }\end{array}$ & LPS, SCFAs, BAs & $\begin{array}{l}\text { Patient \& } \\
\text { animal }\end{array}$ & [45] \\
\hline
\end{tabular}

LPS: lipopolysaccharide; SCFAs: short-chain fatty acids; IL-6: interleukin-6; CXCL2: C-X-C motif chemokine ligand 2; NLRP3: recombinant NLR family, pyrin domain containing protein 3; IL-1 $\beta$ : interleukin- $\beta$; IL-10: interleukin-10; A $\beta$ : amyloid $\beta$-protein; GABA: $\gamma$-aminobutyric acid; BDNF: brain-derived neurotrophic factor; DHA: docosahexaenoic acid; TNF $\alpha$ : tumor necrosis factor- $\alpha$; PUFAs: polyunsaturated fatty acid; Bas: bile acids.

sclerosis, epilepsy, and stroke. The gut-brain axis is adversely affected by the destruction of intestinal epithelial barrier, loss of intestinal neurons, and overproduction of proinflammatory cytokines. In addition, gut microbial abundance and diversity undergo significant changes during neurological disorders, especially that of bacteria producing anti-inflammatory factors. FMT can significantly adjust the richness of intestinal species and restore the proportion of anti-inflammatory bacteria and is therefore increasingly being considered for treating diseases of the nervous system (Table 2).

2.1. Parkinson's Disease. Parkinson's disease (PD) is a progressive neurodegenerative disease characterized by accumulation of Lewy bodies [69]. PD patients often present with GI symptoms such as constipation [70]. According to the theory of intestinal origin of $\mathrm{PD}$, a prion-like neurotrophic protein is misfolded into $\alpha$-synuclein ( $\alpha$-syn) and transported from the GI tract to the central nervous system (CNS) [71]. Studies on the mouse model of PD have confirmed that $\alpha$-syn can indeed be transferred from the gut to the brain by crossing the blood-brain barrier [72]. Consistent with this, several studies $[3,4,73,74]$ have reported considerable differences between the gut microbial composition and metabolites of healthy individuals and PD patients. Scheperjans et al. [73] compared the fecal microbiome of PD patients with that of 72 healthy controls and detected $77.6 \%$ lower prevalence of Prevotellaceae in the former. In addition, PD patients' postural instability and gait difficulty were positively associated with the higher abundance of Enterobacteriaceae, suggesting a causative association between the microbiota-gut-brain axis 


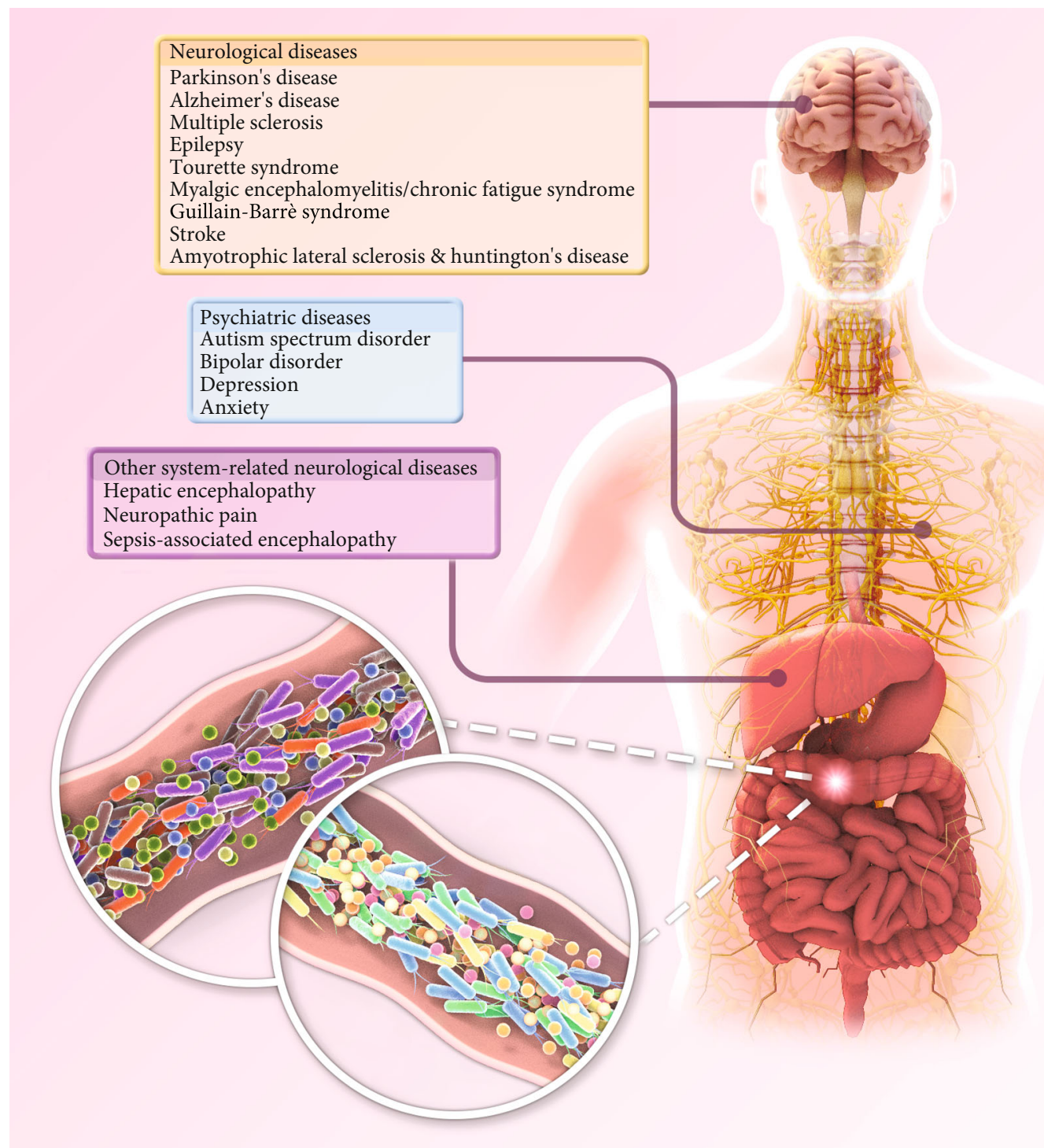

FIGURE 1: Current applications of FMT in various neurological and psychiatric diseases. Normal gut microbiota plays an important role in maintaining the functional stability of the gut-brain axis. Excessive reproduction of pathogenic bacteria or reduction of probiotics can lead to gut microbiota disorder and mediate a variety of neurological and psychological diseases. As an important therapeutic method to reconstruct gut microbiota, FMT has been tried to be applied to a variety of diseases related to gut-brain axis.

and progression of disease. Furthermore, Keshavarzian et al. [4] observed a greater proportion of LPS-producing proinflammatory bacteria (e.g., Ralstonia) and fewer bacteria producing the anti-inflammatory short-chain fatty acids (SCFAs) (e.g., Blautia, Coprococcus, Roseburia, and Faecalibacterium) in the gut of PD patients. Studies $[75,76]$ have shown that L-dopa can be metabolized into dopamine by gut microbial tyrosine decarboxylase, which is not easily affected by aromatic amino acid decarboxylase inhibitors such as carbidopa. In addition, the germ-free $\alpha$-syn overexpressing (ASO) mice exhibited less severe motor and digestive symptoms (constipation), as well as lower microglia activation compared to their SPF counterparts [77], indicating that the gut microbiota is directly involved in PD's development.

Consistent with the above, Sun et al. [78] showed that FMT from healthy mice significantly improved the motor function in $\mathrm{PD}$ mice by mitigating intestinal inflammation and neuroinflammation and increasing the levels of dopamine and 5-hydroxytryptamine. The anti-inflammatory effects were mediated via TLR $4 / \mathrm{bk} 1 / \mathrm{NF}-\kappa \mathrm{B} / \mathrm{TNF}-\alpha$ pathway blockade, reduced activity of microglia and astrocytes, and increased producing SCFAs. In contrast, FMT from PD mice had a pathological effect on healthy recipients. Huang et al. [49] recently reported that three rounds of FMT over a period one week improved constipation and motor symptoms such as leg tremors in a PD patient. However, the tremors recurred 2 months after FMT, whereas constipation was relieved even after 3 months.

2.2. Alzheimer's Disease. Alzheimer's disease (AD) is a neurodegenerative disease characterized by cognitive decline due to the loss of neurons and synapses following deposition of neurofibrillary tangles (NFT) and misfolded amyloid $\beta$ $(\mathrm{A} \beta)$ protein plaques [79]. Several studies $[5,6]$ have shown 


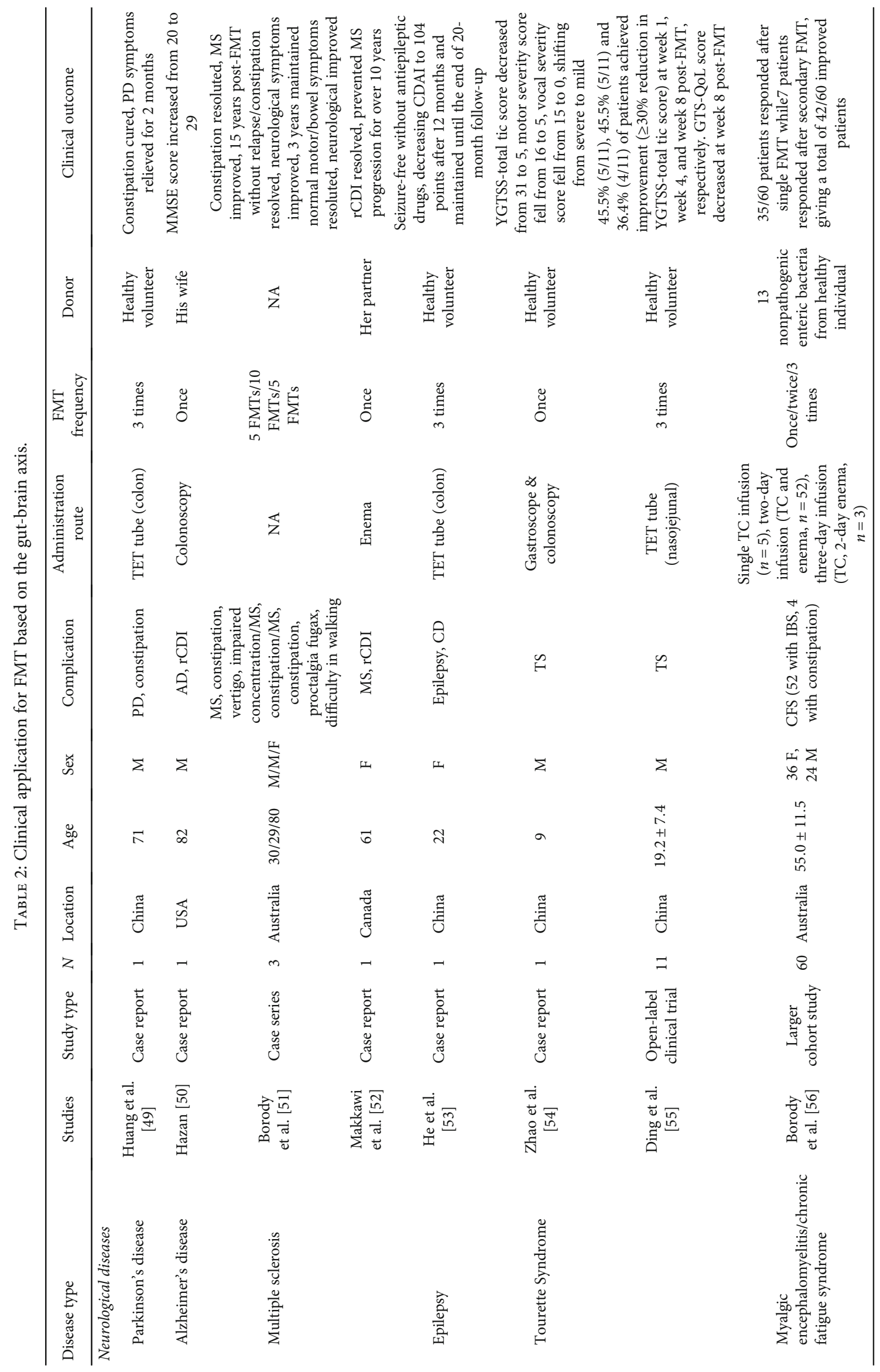




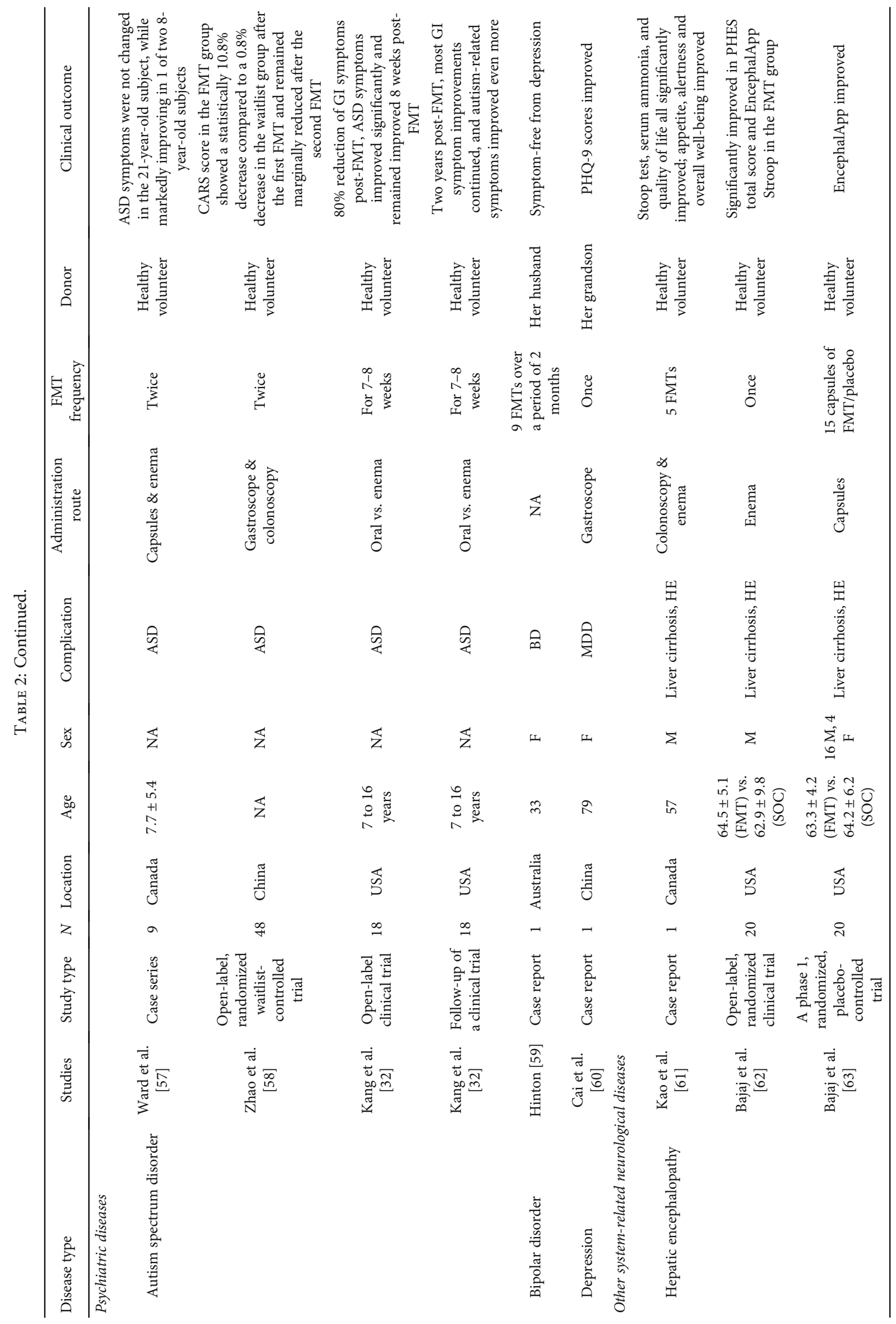




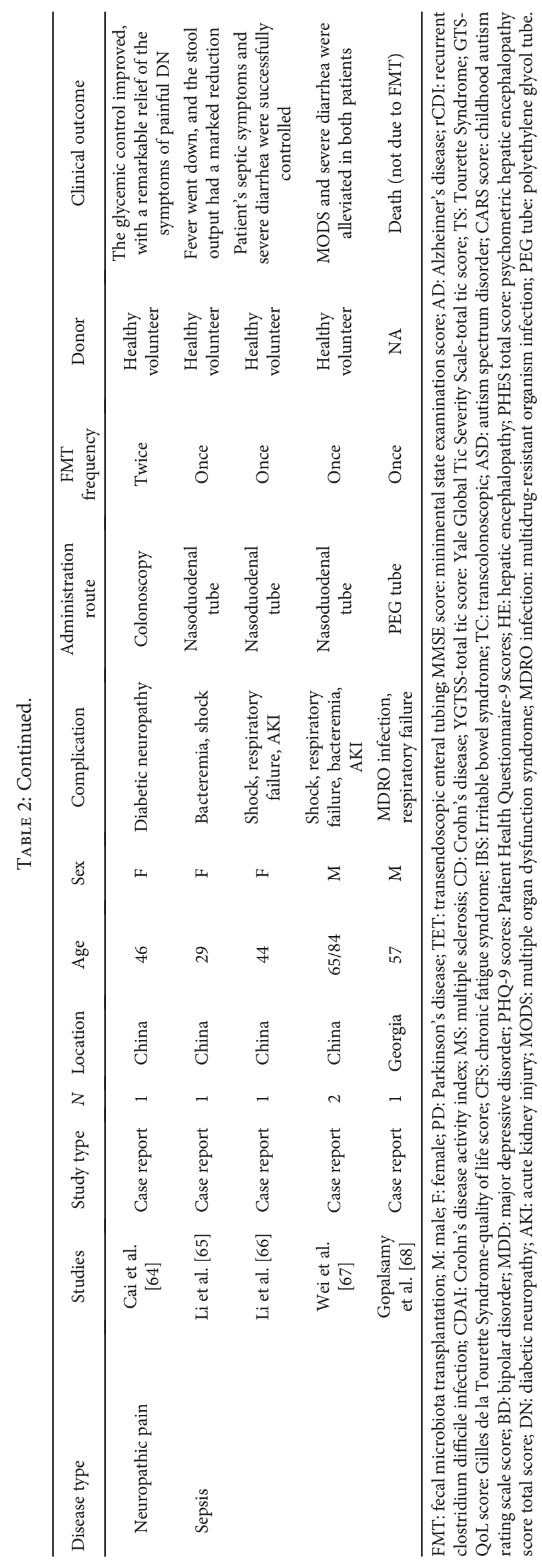


that the gut microbiota composition in $\mathrm{AD}$ patients differs considerably from that of healthy elderly individuals. For instance, the $\mathrm{AD}$ patients have a higher relative abundance of LPSproducing bacteria such as Burkholderiaceae, Staphylococcaceae, Porphyromonas gingivalis, and Propionibacterium acnes, as well as fungi in their intestine compared to healthy controls. In addition, patients with cerebral amyloidosis (Amy+) and cognitive impairment have more proinflammatory bacteria in their feces and higher levels of circulating inflammatory cytokines (IL-6, IL-1 $\beta$, etc.) compared to healthy individuals and Amy- patients [80-84]. Likewise, Cattaneo et al. [85] also detected higher circulating levels of IL-6, IL-1 $\beta$, and other inflammation-related factors like CXCL2 and NLRP3, along with reduced levels of the anti-inflammatory IL-10 in Amy+ patients relative to that in controls and Amy- patients. Furthermore, the Amy+ patients showed lower abundance of Eubacterium rectale and a higher abundance of Escherichia/Shigella compared to both healthy controls and Amy- patients. A significantly positive correlation was observed between the levels of proinflammatory factors and the abundance of Escherichia/Shigella. Several bacterial species are known to secrete neurotransmitters and alter the expression of synaptic plasticity, which may play a role in the pathogenesis of $\mathrm{AD}$ [86]. In addition to these direct effects, some changes in gut microbiota may indirectly promote $\mathrm{AD}$ by triggering neuroinflammation [87]. Consistent with this hypothesis, there are reports that probiotics can improve cognitive function in not only animal models but also AD patients or adults with cognitive impairment [8890]. Furthermore, the age-related decline in cognitive ability may also be related to the concomitant decrease in the number of anti-inflammatory bacteria in the human gut [91, 92].

Recent studies [93, 94] have shown that antibioticmediated depletion of the gut microbiota alleviated $\mathrm{A} \beta$ pathology and neuroinflammation in a mouse model of $\mathrm{AD}$, and the therapeutic effect of antibiotics was partially reversed following FMT from AD mice. In addition, germfree mice receiving feces from healthy old mice had worse cognitive function compared to the recipients of feces from younger mice due to lower fecal levels of nervous systemrelated metabolites (such as GABA) in the former [95]. Kim et al. [96] transplanted the fecal microbiota from health control mice into the recently developed AD-like pathology with amyloid and neurofibrillary tangle (ADLPAPT) transgenic mouse model and observed a significant reduction in cerebral amyloid plaques, NFTs and reactive gliosis, which correlated to improve cognitive and memory function. Hazan [50] reported the case of an 82-year-old AD patient who showed remission of Clostridium difficile infection (CDI) symptoms after receiving a single FMT from his 85year-old wife and a negative stool test 2 months later. Interestingly, the minimental state examination (MMSE) score of the patient increased from 20 (mild cognitive impairment) to 26 (normal cognitive function) 2 months after FMT, and he reported memory retention and significant improvement in mood (MMSE score 29) after 4 and 6 months, respectively.

2.3. Multiple Sclerosis. Multiple sclerosis (MS) is a demyelinating disease of the CNS with uncertain etiology, although genetics, infection, and environmental factors have been implicated as key pathological factors [97]. The gut microbiota regulates the production of myelin sheath in the prefrontal cortex of mice $[98,99]$ and maintains the integrity of the blood-brain barrier [100] by producing SCFAs [101]. This is suggestive of a dysregulated gut microbiome in MS since the loss of blood-brain barrier integrity is also a cardinal sign of this disorder. In addition to the direct role in demyelination and blood-brain barrier disruption, the gut microbiota and its metabolites also regulate neuroinflammation [102104], although the exact relationship between gut microorganisms and MS-related neuroinflammation needs a further study. The intestinal microbiota of MS patients have a lower relative abundance of Treg cell-inducing bacteria $[9,105]$, which may increase the proportion of peripheral Th1 and Th17 cells [98]. In addition, the risk of relapse in MS patients is associated with the depletion of Fusobacteria, expansion of the phylum Firmicutes, and presence of Archaea (Euryarchaeota) [106]. Oral gavage with Prevotella histicola not only reduced the severity of symptoms in a mouse model of MS but also decreased the number of Th1 and Th17 cells, while increasing that of Treg cells [107]. A randomized control trial (RCT) on $40 \mathrm{MS}$ patients showed that probiotic (Lactobacillus acidophilus, Lactobacillus casei, Bifidobacterium bifidum, and Lactobacillus fermentum) supplementation for 12 weeks significantly increased the circulating levels of IL- 8 and TNF- $\alpha$ and improved the expanded disability status scale (EDSS) scores [108].

The clinical and pathophysiological characteristics of MS are best simulated in the experimental autoimmune encephalomyelitis (EAE) mouse model [109]. Oral gavage of the fecal microbiota from MS patients exacerbated the symptoms in EAE mice and decreased the levels of the anti-inflammatory cytokine IL-10 [98, 110]. Li et al. similarly showed that FMT from healthy mice alleviated the symptoms in EAE mice by reducing activity of microglia and astrocytes and restoring the blood-brain barrier integrity and axonal myelination [111]. The therapeutic effects of FMT in MS have been reported in only two studies so far $[51,52]$. In one patient with secondary progressive MS complicated with recurrent CDI, FMT mitigated the recurrent infection and prevented disease progression of MS. However, the EDSS score of the patient stabilized without any improvements in the symptoms. Therefore, although FMT has limited therapeutic effect; it has the potential to provide long-term benefits for MS patients [52]. Furthermore, $3 \mathrm{MS}$ patients with severe constipation were able to defecate normally after FMT, and their exercising ability was also improved significantly [51].

2.4. Epilepsy. Epilepsy is a chronic disease characterized by the sudden abnormal discharge from cerebral neurons, which leads to transient brain dysfunction. The individual susceptibility to epilepsy is associated with genetic and environmental factors, although the exact etiology of most cases remains unclear [16]. Nevertheless, the composition and distribution of gut microbes in patients with intractable epilepsy are distinct from that in healthy controls $[17,112,113]$. Peng et al. [17] found that compared to drug-sensitive patients, the intestinal Firmicutes/Bacteroides ratio and $\alpha$-diversity were significantly higher in the drug-resistant patients. Interestingly, the 
$\alpha$-diversity of the latter was similar to that of healthy controls, most likely due to an aberrant increase in the number of rare bacterial genera such as Clostridium XVIII, Atopobium, Holdemania, Dorea, Saccharibacteria, Delftia, Coprobacillus, Paraprevotella, Ruminococcus, Gemmiger, Akkermansia, Neisseria, Coprococcus, Fusobacterium, Methanobrevibacter, Phascolarctobacterium, and Roseburia. In addition, the increased abundance of Bifidobacterium and Lactobacillus was associated with fewer seizures per year, and a ketogenic diet reduced the frequency of seizures by modulating the gut microbiota [114]. Sewal et al. [115] further observed that intraperitoneal injection of LPS increased the frequency of epileptic symptoms, which was accompanied by an increase in the bloodbrain barrier permeability and in the cerebral levels of proinflammatory cytokines. Antibiotics can protect against epileptic seizures by altering the bacterial population, although there is evidence that they may even induce epilepsy [16]. In addition, probiotic strains such as Lactobacillus acidophilus, Lactobacillus plantarum, Lactobacillus casei, Lactobacillus helveticus, Lactobacillus brevis, Bifidobacterium lactis, Streptococcus salivarius subsp., and Thermophilus have also shown a positive effect in epilepsy patients $[116,117]$. Olson et al. [118] observed that transplantation of ketogenic microbiota decreased the number of seizures in mice at a higher threshold. He et al. [53] reported a case of epilepsy complicated with Crohn's disease in a 17-year-old patient who showed improvements in neurological and intestinal symptoms following three rounds of FMT. Antiepileptic therapy with sodium valproate was discontinued after 20 months, and no epileptic seizures were observed.

2.5. Tourette Syndrome. Tourette Syndrome (TS) is a neurodevelopmental disorder characterized by motor and speech tics in childhood [119]. Liao et al. [120] found that probiotic supplementation improved tic-like behavior in mice, which coincided with an increased level of dopamine and norepinephrine. A study on 30 pediatric acute-onset neuropsychiatric syndrome and pediatric autoimmune neuropsychiatric disorders associated with streptococcal infections syndrome patients revealed a significantly different gut microbial composition compared to that of healthy controls [18]. Another study found that [121] antibiotics that effectively reduce streptococcal infections can also mitigate the associated tic disorders. Zhao et al. [54] reported that FMT eliminated involuntary articulation, reduced involuntary shrugging, and increased attention span in a pediatric case of TS over a period of 8 weeks. In an open label clinical trial [55], 11 TS patients experienced a transient decrease in seizure severity following three rounds of FMT.

2.6. Myalgic Encephalomyelitis/Chronic Fatigue Syndrome. Myalgic encephalomyelitis/chronic fatigue syndrome (ME/CFS) is characterized by unexplained persistent fatigue, disturbed sleep, cognitive impairment, fever, postural intolerance, lymphadenopathy, and irritable bowel syndrome. The gut microbiota is significantly altered in patients with ME/CFS [19], and the extent of microbial dysbiosis affects disease severity [122]. Sheedy et al. [123] observed increased relative abundance of gram-positive lactic acid-producing bacteria in the gut of ME/CFS patients, which may lower the mucosal $\mathrm{pH}$ and increase permeability. Moreover, the transfer of lactic acid from intestine to the blood may be one of the reasons for the increase of lactate level in cerebrospinal fluid of ME/CFS patients [124-126]. Selective transplantation of 13 nonpathogenic enteric bacteria through colonoscopy [56] significantly improved intestinal and other symptoms in $42 / 60 \mathrm{ME} / \mathrm{CFS}$ patients. In addition, 7/12 patients who were followed up for 15 to 20 years showed complete remission, indicating FMT is a promising treatment for ME/CFS.

2.7. Guillain-Barré Syndrome. Guillain-Barré Syndrome (GBS) is a paralytic autoimmune neuropathy caused by infection, especially Campylobacter jejuni infection in the GI tract, or other immune stimulation [127]. The innate immune response to campylobacteriosis is characterized by the accumulation of neutrophils and macrophages, inflammatory damage to the mucosa, gut barrier defects, and malabsorption, which eventually lead to bloody diarrhea [23]. Mice inoculated with Campylobacter jejuni from GBS patients showed increased levels of autoantibodies and peripheral nerve injury $[128,129]$, indicating a close association between gut dysbiosis and GBS pathogenesis. In fact, the cross-reaction between LPS produced by Campylobacter jejuni, and the peripheral gangliosides is one of the causative factors of GBS [130]. The combination of antibiotics and FMT significantly expedited Campylobacter jejuni clearance from the infected mice [131]. In addition, Brooks et al. [132] observed that human FMT increased the Th2 and autoimmune response in mice infected with Campylobacter jejuni. Finally, the outer core LPS of Campylobacter jejuni can directly initiate the peripheral neuropathy of GBS by inducing production of neurotoxic antiganglioside autoantibodies [133].

2.8. Stroke. Stroke is an acute cerebrovascular accident characterized by muscular and sensory weakness. Studies show that the composition of gut microbiota of stroke patients differs considerably from that in healthy controls $[134,135]$, although there are some reports indicating transient or no change [136]. Furthermore, the possible role of gut dysbiosis in stroke is ambiguous [137]. One study showed that a stroke episode decreased intestinal motility and $\alpha$-diversity and led to bacterial overgrowth, intestinal barrier damage, and increased infiltration of inflammatory immune cells in the gut-associated lymphoid tissue and brain, eventually increasing the infarct volume [138]. In addition, the translocation of gut microbiota and their metabolites may also be involved in the pathogenesis of stroke [139]. For instance, trimethylamine-N-oxide produced by gut microbiota may be associated with a higher risk of atherosclerosismediated cardiovascular events, including stroke [140, 141]. Prebiotic treatment exacerbated the functional damage and inflammation in a mouse model of stroke, which increased the infarct volume [138, 142]. However, transplantation of healthy microbiota reduced infarct volume [138], indicating that FMT can be considered for treating stroke patients.

2.9. Amyotrophic Lateral Sclerosis and Huntington's Disease. Amyotrophic lateral sclerosis (ALS), also known as motor neuron disease (MND), is a neurodegenerative disorder 
characterized by progressive atrophy of the limb, trunk, chest, and abdomen muscles following upper and lower motor neuron injury [143]. The mouse model of ALS shows an altered gut microbiota structure compared to healthy mice, such as a lower relative abundance of butyrateproducing bacteria [144]. Although a definitive pathological role of the gut microbiota in ALS has not been reported in humans [26], the clinical potential of FMT is still being explored [145]. Huntington's disease is caused by an autosomal dominant mutation in the huntingtin gene and is inherited in most cases. Nevertheless, several studies have implicated nongenetic factors in the development of Huntington's disease, such as the gut microbiota. Metabonomics analysis of the sera of preonset and early onset Huntington's disease patients and healthy controls showed significant differences in the gut microbiota metabolites across all groups [146], indicating that changes in the microflora determine disease course. The role of gut dysbiosis in the pathogenesis of Huntington's disease has also been confirmed in a murine transgenic model [29]. However, further studies are needed to fully understand the causative role of the gut microbiota and its metabolites in the genesis, progression, and severity of Huntington's disease.

\section{Psychiatric Diseases}

There is growing evidence that gut dysbiosis also contributes to mental health and psychiatric disorders, such as autism spectrum disorder, bipolar disorder, depression, anxiety, obsessive-compulsive disorder, posttraumatic stress disorder, schizophrenia, and dementia through the gut-brain axis [147, 148]. FMT has gained attention as a viable therapeutic option for these conditions (Table 2).

3.1. Autism Spectrum Disorder. Autism spectrum disorder (ASD) is a group of neurodevelopmental disorders characterized by changes in social interaction and repetitive, stereotypical behavior [149]. Recent studies show that gut microbial community and metabolites of ASD patients are distinct from that of healthy individuals $[8,150]$. Although a putative relationship between gut dysbiosis and ASD behavior has been established in rodent models and human subjects, studies have not been sufficient to confirm the causal relationship between gut microbiota and ASD symptoms. The predominant phyla of the healthy adult human gut are Bacteroidetes (e.g., Bacteroides and Prevotella), Firmicutes (e.g., Clostridium, Lactobacillus, and Ruminococcus), Proteobacteria (e.g., Enterobacter), and Actinobacteria (e.g., Bifidobacterium) and constitute more than $90 \%$ of the gut microbiota [151, 152]. Since germ-free mice are socially dysfunctional compared to wild-type mice, the gut microbiota likely play an important role in normal behavior [153]. Regular administration of probiotics including Lactobacillus reuteri, Lactobacillus plantarum, Lactobacillus acidophilus, Lactobacillus rhamnosus, and Bifidobacterium longum over a period of 3 weeks to 6 months improved autistic symptoms significantly in ASD children [154-156]. Lactobacillus rhamnosus and a placebo were, respectively, administered to 40 and 35 infants for the first 6 months of life in an RCT, and all subjects were followed over 13 years. Six infants of the placebo group were diagnosed with Asperger's syndrome or attention deficit hyperactivity disorder during the follow-up period whereas none in the probiotic group exhibited any signs of autism, indicating that early administration of probiotics can potentially reduce the risk of developing ASD [155]. A recent study has shown that there is a causal relationship between maternal diet, changes in gut microbiota, and social behavior. Among female neonatal rats fed with a high-fat diet, female rats born on a high-fat diet and for more than 4 weeks Lactobacillus reuteri restored gut microbial diversity and significantly improved their social behavior [157].

Sharon et al. [158] found that germ-free mice transplanted with the feces from children with ASD exhibited similar symptoms. In addition, the offspring of these FMT recipients also experienced these symptoms and showed alternative splicing of ASD-related genes in the brain. Likewise, FMT from healthy hamsters alleviated the ASD-like symptoms in the autism hamster model [159] by alleviating the brain oxidative stress response. In an open clinical trial on 18 children with ASD, FMT for 7 to 8 weeks could significantly improve digestive symptoms (abdominal pain, constipation, diarrhea, and indigestion) and the behavioral symptoms [32]. Furthermore, FMT also improved the bacterial diversity by significantly increasing the abundance of Bifidobacterium, Desulfovibrio, and Prevotella. The therapeutic effects persisted for 8 weeks after ceasing treatment. In another study, the ASD symptoms improved in 8/9 recipients of FMT and antibiotic treatment [57]. Zhao et al. [58] conducted an open label RCT on 24 autistic and 24 normal children that were treated with FMT for 2 months. Although FMT improved the behavioral and GI symptoms, the effects were transient.

3.2. Bipolar Disorder. Bipolar disorder (BD) is a type of mood disorder that clinical manifests as distinct episodes of depression, manic seizures, and their combination. Both the diversity and taxonomic composition of the gut microbiota in BD patients are significantly different from that of healthy individuals [36]. Painold et al. [160] further showed that the phylum Actinobacteria and class Coriobacteria were significantly more abundant in the gut of BD patients, whereas Ruminococcaceae and Faecalibacterium were more abundant in the healthy controls as per $16 \mathrm{~S}$ rRNA gene sequencing and LEfSE analysis. They also observed a negative correlation between microbial $\alpha$-diversity and duration of $\mathrm{BD}$ and identified bacterial clades associated with inflammatory status, serum lipids, depressive symptoms, oxidative stress, anthropometrics, and metabolic syndrome in the $\mathrm{BD}$ patients. $\mathrm{Hu}$ et al. [35] analyzed the gut microflora of $52 \mathrm{BD}$ patients and 45 controls and found that the $\alpha$-diversity of untreated $\mathrm{BD}$ patients was lower than that of the control group, and the predominant phyla were Bacteroidetes and Firmicutes, respectively. In addition, butyrate-producing bacteria were less abundant in the untreated patients, which was restored following quetiapine treatment. Furthermore, probiotics supplementation for a period of 3 months improved the cognitive and executive functions of $20 \mathrm{BD}$ patients [161].

Hinton [59] reported a case of a 29-year-old female patient diagnosed with type I DSM-IV BD who had been 
treated with various drugs, including lithium, lamotrigine, valproate, quetiapine, olanzapine, and various benzodiazepines, that led to significant weight gain and poor quality of life. Nine rounds of FMT in 11 months not only alleviated depression and mania but also helped her lose the excess weight and remain asymptomatic without using other drugs.

3.3. Depression. Depression is a common mental disease typically characterized by persistent feelings of sadness and loss of interest in daily activities. It results from a combination of both genetic and environmental factors, and a major cause is stress [162]. Studies increasingly show that the gut microbiota can shape cognition through the microbiota gut-brain axis, and mice with altered microbiota usually exhibit depression-related behaviors [163]. Kelly and Borre [164] analyzed the intestinal flora of 34 patients with depression and 33 matched healthy subjects and found that the microbial abundance and biodiversity were decreased in the patient group. FMT from these patients into germ-free rats induced depression-like behavior such as lack of pleasure and anxiety in the latter, along with increased levels of tryptophan. A meta-analysis of 71 studies published between 2003 and 2019 [165] further revealed that probiotics and prebiotics can significantly improve symptoms of anxiety and depression compared to untreated or placebo-treated controls and provide additional benefits to patients with other diseases such as irritable bowel syndrome.

Zhang et al. [163] found that FMT from depressed patients into germ-free mice led to depressive behavior in the latter. Similar results were observed after antibiotic treatment as well. Furthermore, FMT from the NLRP3-knockout mice significantly improved the behavioral symptoms in a mouse model of depression. Likewise, Xie [166] also found that the fecal microbiota of healthy mice alleviated depressive symptoms. In a recent case report [60] of an older woman diagnosed with depression, a single FMT improved sleep cycle, appetite, and general mood within 4 days of treatment. The patient was able to live independently after 2 weeks and showed an increase in weight. Six months later, her weight had returned to normal, constipation symptoms had improved, and the Patient Health Questionnaire-9 score decreased from 21 to 4 .

3.4. Anxiety. Anxiety is one of the most common types of neurosis and is characterized by feelings of tension/worry without a clear objective, restlessness, and autonomic nerve dysfunction. Clinically, it is classified into chronic/generalized anxiety and acute anxiety or panic attack [167]. A large case-control study [168] showed that the use of antibiotics increased the risk of anxiety and depression, and the risk increased with the frequency of usage, suggesting a causative or ancillary role of the gut microbiota. Furthermore, there is evidence that depression can lead to secondary changes in the composition of the gut microbiota, resulting in a regulatory feedback loop between depression and dysbacteriosis [169]. Compared to the SPF mice, sterile mice showed significantly higher anxiety in the elevated maze test, and oral administration of the JB-1 probiotic strain effectively reduced the anxious behavior and improved performance. Furthermore, a systematic review of 21 studies including 1503 subjects with anxiety disorders concluded that microbiota-targeted therapies [41], including probiotics supplements, single probiotics, double probiotics, multiple probiotics, dietary fiber supplement, and low FODMAP diet, can alleviate symptoms of anxiety by regulating the gut microbiota.

De Palma et al. [170] transplanted fecal microbiota from healthy control and diarrhea-predominant irritable bowel syndrome (IBS) patients with (IBS-A) or without anxiety into germ-free mice and analyzed the changes in intestinal function and behavior. The gut microbiota of mice transplanted with the feces of IBS patients showed unique clustering characteristics compared to that of control fecal recipients. Anxiety-like behavior was determined with the light/dark preference test and platform jumping test, which showed that the IBS-A recipient mice had the least preference for light and showed the delay in jumping off a high platform, both of which are indicative of a higher degree of anxiety. These studies clearly indicate the involvement of gut dysbiosis in the severity of anxiety symptoms.

\section{Other System-Related Neurological Diseases}

Several neurological and psychological diseases are frequently complicated with digestive system symptoms. Likewise, some diseases predominantly affecting the nonnervous systems may also have a neurological component and are commonly manifested as encephalopathies. For instance, decompensated hepatic encephalopathy and peripheral neuropathy are severe complications of cirrhosis and diabetes, respectively, and sepsis patients often present delirium, coma, and other neurological symptoms. The role of the gut microbiota in these encephalopathies is increasingly being recognized, thereby indicating the therapeutic potential of FMT for these diseases (Table 2).

4.1. Hepatic Encephalopathy. Hepatic encephalopathy (HE) is a serious complication of cirrhosis and is caused by brain dysfunction. The increased content of hepatic ammonia in cirrhosis patients with mild HE indicates the pathological involvement of intestinal dysbiosis. For instance, the intestinal tract of cirrhotic patients with/without mild HE frequently harbors urease-positive Streptococcus salivarius, which is absent in healthy individuals [171]. Thus, S. salivarius is a promising therapeutic target in liver cirrhosis patients with mild HE. Sung et al. [43] confirmed that fecal microbiota can predict the clinical prognosis of patients with liver cirrhosis and HE, such as Lactobacillus, Bacteroides, Clostridium_incertae_sedisof, and Clostridium XI, which were associated with patients' mortality. Furthermore, Kawaguchi et al. [172] showed that rifaximin improved both liver and neuropsychological function in liver cirrhosis patients with $\mathrm{HE}$ by adjusting the gut microbial structure.

A promising case study of a 57-year-old patient with $\mathrm{HE}$ due to alcoholic and hepatitis $C$ cirrhosis [61] showed that FMT in addition to lactulose objectively improved reaction time, serum ammonia, and quality of life scores. However, these improvements were transient and subsided to the baseline levels within 7 weeks of FMT cessation. Furthermore, Bajaj et al. [62] conducted an RCT on male cirrhotic patients 
diagnosed with recurrent $\mathrm{HE}$ and found that FMT reduced hospitalization rate and improved cognitive ability in these patients during the 5-month follow-up. In another clinical trial conducted by Bajaj et al. [63], administration of FMT capsules to HE patients restored the gut microflora by significantly increasing the abundance of Bifidobacterium and Ruminococcaceae and decreasing that of pathogenic genera like Streptococcus and Veillonella. The FMT-induced changes in the gut microbiota led to an increase in duodenal Ecadherin and defensin- $\alpha 5$ expression and reduced serum levels of IL-6 and LBP.

4.2. Neuropathic Pain. Neuropathic pain is caused by peripheral or CNS injury (such as nerve injury or chemotherapy injury) or diabetes and is characterized by abnormal sensations or pain even after normal stimulations [173]. The composition and function of the gut microbiota in diabetic patients differ significantly from that of healthy controls [174]. FMT from conventionally reared mice increased the insulin resistance in germ-free mice [175], whereas subjects with metabolic syndrome showed increased insulin sensitivity following FMT [176]. Gut microbiota can also directly regulate the excitability of spinal dorsal root neurons or indirectly regulate inflammation in the peripheral and central nervous system [177]. Oxaliplatin can cause peripheral neuropathy and pain, but this phenomenon is not obvious in mice with antibiotic cleaning or in mice with complete loss of gut microbiota. Furthermore, if FMT was performed on the appellate mice, the pain would be restored, indicating that the gut microbiota has an effect on neuropathic pain [178]. Another study found that probiotics alleviated the characteristics of paclitaxel-induced neuropathic pain in vitro [179], although their efficacy is dependent on the type of neuropathic pain. For instance, Lactobacillus Reuteri or Bifidobacterium were not effective against the neuropathic pain induced by chronic compression injury in rats [180].

A case study [64] of a woman with type 2 diabetes mellitus and diabetic neuropathy showed that two rounds of FMT improved limb pain and paresthesia, which was manifested as decreased visual analogue pain score (VAS) and increased tibial nerve motor conduction velocity, without any significant improvement in EMG sensory dysfunction. In addition, the fasting blood glucose level also decreased and stabilized, and glycosylated hemoglobin content decreased post-FMT.

4.3. Sepsis-Associated Encephalopathy. Sepsis is an acute systemic infection caused by various pathogenic bacteria that invade the bloodstream and rapidly proliferate and produce life-threatening toxins. Sepsis-associated encephalopathy is a key neurological manifestation of sepsis, with symptoms ranging from delirium to coma. It occurs in almost $70 \%$ of the ICU patients and is associated with higher ICU and hospital mortality, as well as poor long-term outcomes (including cognitive and functional outcomes) [181, 182]. The toxins and other harmful antigens secreted by pathogenic bacteria or viruses can be neutralized by the antibodies produced by antigen-primed B cells. Intestinal microorganisms have been shown to induce the clonal expansion of specific $\mathrm{B}$ cell populations and increase production of antibodies to prevent the spread of infection [183]. Li et al. found that FMT effectively improved the spatial memory and EEG abnormalities in an LPS-induced rat model of sepsis combined with cervical vagotomy, and the therapeutic effect of FMT was likely mediated through the vagus nerve [184]. In addition, several case reports indicate that non-CDI sepsis patients with prolonged ICU stay and complications including bacteremia, MDR bacterial infection, respiratory failure, and organ dysfunction significantly benefitted from FMT. A total of 5 patients received FMT, of which 4 showed clinical improvement and 1 died from non-FMT-related causes [65-68].

\section{Discussion}

Nervous system diseases are highly complex and show cognitive, motor, and even systemic manifestations. Given that gut dysbiosis is a potential causative factor of neurological dysfunction, FMT-mediated restoration of the gut microbiota can stall the symptoms or progression of nervous system diseases through immune, endocrine, metabolic, and/or neural pathways. The metabolites and cytokines produced by gut bacteria determine intestinal and systemic inflammation and, therefore, the intestinal barrier function. However, there are several limitations of using FMT in treating neurological, mental, and psychological diseases: (1) for many diseases, the therapeutic effects of FMT are limited to animal models and isolated cases. Although transplantation of human feces to animal models has shown encouraging results, the GI and physiological differences between humans and animals preclude the extrapolation of the results to sick or healthy humans. (2) The fecal feeding behavior often observed in mice [185] may also affect the microbiota analysis and the efficacy of FMT. In addition, animals housed in the same cage may have a closer gut microbial structure, which can also affect the results. (3) The efficacy of FMT depends on the types of antibiotics, microbial composition, intervention procedure, and donors. The exact influence of these factors and the potential adverse effects of FMT are currently unknown due to lack of long-term follow-up and appropriate controls. Therefore, it is crucial to establish scientific standards in order to gauge the therapeutic efficacy of FMT [186]. (4) The role of the gut microbiota in the early development of nervous system also needs to be elucidated. For instance, a study on 39 infants showed that the $\alpha$-diversity of gut microbiota was also associated with functional connectivity between the auxiliary motor area and the inferior parietal lobule, and this functional connectivity affects the cognitive level at 2 years of age [187]. (5) Many successful cases of FMT in the treatment of neurological diseases/psychiatric diseases often have obvious GI symptoms, and the improvement of neurological symptoms/mental symptoms is also related to the GI symptoms. For patients with neurological diseases/psychiatric diseases but without obvious GI symptoms, whether the curative effect of FMT will be reduced or unchanged is also worth our concern.

Despite the promising results, the rationale for the clinical application of FMT is currently based on animal models and a few case reports and clinical studies. Large-scale randomized double-blind controlled trials are still needed to clarify the role of FMT in neurological diseases. At present, 
TABLE 3: Clinical trials of FMT involving in nervous and mental disease.

\begin{tabular}{|c|c|c|c|c|c|}
\hline NCT number & Conditions & FMT route & Phases & Status & Locations \\
\hline NCT02255617 & Hepatic encephalopathy & Colonoscopy \& enema & $\begin{array}{l}\text { Phase } 1 \\
\text { phase } 2\end{array}$ & Completed & Canada \\
\hline NCT02636647 & Hepatic encephalopathy & Enema & Phase 1 & Completed & $\begin{array}{l}\text { United } \\
\text { States }\end{array}$ \\
\hline NCT03420482 & Hepatic encephalopathy & Capsules & Phase 2 & Recruiting & $\begin{array}{l}\text { United } \\
\text { States }\end{array}$ \\
\hline NCT03152188 & Hepatic encephalopathy & Capsules & Phase 1 & Completed & $\begin{array}{l}\text { United } \\
\text { States }\end{array}$ \\
\hline NCT03439982 & Hepatic encephalopathy & Colonoscopy \& enema & $\begin{array}{l}\text { Phase } 1 \text {, } \\
\text { phase } 2\end{array}$ & Recruiting & Canada \\
\hline NCT03796598 & Hepatic encephalopathy & Capsules \& enema & $\begin{array}{l}\text { Phase } 1 \text {, } \\
\text { phase } 2\end{array}$ & Recruiting & $\begin{array}{l}\text { United } \\
\text { States }\end{array}$ \\
\hline NCT03408886 & Autism spectrum disorder & Pill (no detail) & Phase 2 & Recruiting & $\begin{array}{l}\text { United } \\
\text { States }\end{array}$ \\
\hline NCT03426826 & Autism spectrum disorder & Gastroscope & Phase 1 & Recruiting & $\begin{array}{l}\text { United } \\
\text { States }\end{array}$ \\
\hline NCT03829878 & Autism spectrum disorder & Capsules & Phase 2 & $\begin{array}{l}\text { Not yet } \\
\text { recruiting }\end{array}$ & $\begin{array}{l}\text { United } \\
\text { States }\end{array}$ \\
\hline NCT04182633 & Autism spectrum disorder & Oral administration of FM (no detail) & Phase 2 & Recruiting & $\begin{array}{l}\text { United } \\
\text { States }\end{array}$ \\
\hline NCT04246398 & Children with autism & Capsules & $\begin{array}{c}\text { Not } \\
\text { applicable }\end{array}$ & $\begin{array}{l}\text { Not yet } \\
\text { recruiting }\end{array}$ & Israel \\
\hline NCT03026231 & Parkinson's disease & Capsules & $\begin{array}{l}\text { Phase } 1 \\
\text { phase } 2\end{array}$ & Withdrawn & $\begin{array}{l}\text { United } \\
\text { States }\end{array}$ \\
\hline NCT03671785 & Parkinson disease & Capsules & Phase 1 & Recruiting & $\begin{array}{l}\text { United } \\
\text { States }\end{array}$ \\
\hline NCT03808389 & Parkinson disease & Nasojejunal & $\begin{array}{c}\text { Not } \\
\text { applicable }\end{array}$ & Recruiting & Belgium \\
\hline NCT03876327 & Parkinson disease & Not applicable & $\begin{array}{l}\text { Phase } 2 \text {, } \\
\text { phase } 3\end{array}$ & Completed & Israel \\
\hline NCT03183869 & Multiple sclerosis & Enema & Phase 2 & Terminated & Canada \\
\hline NCT03594487 & Multiple sclerosis & Colonoscopy & Phase 1 & Recruiting & $\begin{array}{l}\text { United } \\
\text { States }\end{array}$ \\
\hline NCT03975413 & Multiple sclerosis & Not applicable & $\begin{array}{c}\text { Not } \\
\text { applicable }\end{array}$ & $\begin{array}{l}\text { Active, not } \\
\text { recruiting }\end{array}$ & $\begin{array}{l}\text { United } \\
\text { States }\end{array}$ \\
\hline NCT04203017 & Multiple sclerosis & Capsules & Phase 1 & Recruiting & $\begin{array}{l}\text { Russian } \\
\text { Federation }\end{array}$ \\
\hline NCT03691987 & $\begin{array}{l}\text { Chronic fatigue syndrome/myalgic } \\
\text { encephalomyelitis }\end{array}$ & Enema & Phase 2 & Recruiting & Norway \\
\hline NCT04158427 & $\begin{array}{l}\text { Chronic fatigue syndrome/myalgic } \\
\text { encephalomyelitis }\end{array}$ & Colonoscopy & $\begin{array}{c}\text { Not } \\
\text { applicable }\end{array}$ & $\begin{array}{l}\text { Enrolling by } \\
\text { invitation }\end{array}$ & Finland \\
\hline NCT03233100 & $\begin{array}{l}\text { Depressive symptoms, anxiety symptoms, } \\
\text { gut-brain disorders }\end{array}$ & Not applicable & $\begin{array}{c}\text { Not } \\
\text { applicable }\end{array}$ & $\begin{array}{l}\text { Unknown } \\
\text { status* }\end{array}$ & China \\
\hline NCT03281044 & Major depressive disorder & Capsules & Phase 2 & Terminated & Switzerland \\
\hline NCT04001439 & Depression in schizophrenia & Capsules & $\begin{array}{l}\text { Not } \\
\text { applicable }\end{array}$ & $\begin{array}{l}\text { Not yet } \\
\text { recruiting }\end{array}$ & France \\
\hline NCT03998423 & Alzheimer disease & Capsules & Phase 1 & Terminated & $\begin{array}{l}\text { United } \\
\text { States }\end{array}$ \\
\hline NCT02889627 & Epilepsy & $\begin{array}{l}\text { Microbiota suspension infused into } \\
\text { midgut or lower gut (no detail) }\end{array}$ & $\begin{array}{l}\text { Phase 2, } \\
\text { phase } 3\end{array}$ & Recruiting & China \\
\hline NCT03279224 & Bipolar depression & Colonoscopy & $\begin{array}{l}\text { Phase 2, } \\
\text { phase } 3\end{array}$ & Recruiting & Canada \\
\hline
\end{tabular}


TABLE 3: Continued.

\begin{tabular}{|c|c|c|c|c|c|}
\hline NCT number & Conditions & FMT route & Phases & Status & Locations \\
\hline NCT03766321 & Amyotrophic lateral sclerosis & Nasojejunal & $\begin{array}{c}\text { Not } \\
\text { applicable }\end{array}$ & Recruiting & Italy \\
\hline NCT04132427 & Pitt-Hopkins syndrome & Oral (no detail) & Phase 2 & Recruiting & $\begin{array}{l}\text { United } \\
\text { States }\end{array}$ \\
\hline NCT03416751 & Alcohol abuse & Enema & Phase 1 & Completed & $\begin{array}{l}\text { United } \\
\text { States }\end{array}$ \\
\hline NCT03928808 & Anorexia nervosa & Nasogastric tube & $\begin{array}{c}\text { Early } \\
\text { phase } 1\end{array}$ & Suspended & $\begin{array}{l}\text { United } \\
\text { States }\end{array}$ \\
\hline NCT02336789 & $\begin{array}{l}\text { Disorientation as to people, time and } \\
\text { place }\end{array}$ & Colonoscopy & $\begin{array}{c}\text { Not } \\
\text { applicable }\end{array}$ & $\begin{array}{l}\text { Unknown } \\
\text { status* }\end{array}$ & Israel \\
\hline NCT04014413 & $\begin{array}{l}\text { Hepatic encephalopathy, multiple } \\
\text { sclerosis, autism, alcohol dependence }\end{array}$ & Not applicable & $\begin{array}{c}\text { Not } \\
\text { applicable }\end{array}$ & Recruiting & China \\
\hline
\end{tabular}

* Study has passed its completion date, and status has not been verified in more than two years. Date from https://clinicaltrials.gov/.

33 clinical trials are ongoing on the potential therapeutic effects of FMT on mental and nervous system diseases (Table 3). Furthermore, the modes of delivering fecal microbiota also need to be improved. While a capsular form is more comfortable for the patients, fecal bacterial liquid in the form of washed/selective microbiota transplantation [188, 189] may be more effective in reducing the potential side effects.

\section{Data Availability}

Data from the review are available upon request from the corresponding authors (Y.Q.N. and Y.J.Z.).

\section{Conflicts of Interest}

The authors declare no competing financial interests.

\section{Authors' Contributions}

H.M.X., H.L.H., and Y.L.Z. are involved in the design of the study and drafting of the article. H.L.Z. and J.X. are involved in the statistical analysis and interpretation of the data. D.W.S. and Y.D.L. are involved in the design of the figure and tables. Y.J.Z. and Y.Q.N. planned and directed the project and interpreted the results. All authors read and approved the final manuscript. H.M.X., H.L.H., and Y.L.Z. contributed equally to this article.

\section{Acknowledgments}

This work was supported by the grants from the National Natural Science Foundation of China (81700487, 81871905), Guangdong Medical Science and Technology Research Fund (A2019243), Guangzhou Planned Project of Science and Technology (202002020012, 202002030288, and 202002030293), and Innovative Clinical Technique of Guangzhou (2019GX05).

\section{References}

[1] M. J. Bull and N. T. Plummer, "Part 1: the human gut microbiome in health and disease," Integrative Medicine: A Clinician's Journal, vol. 13, no. 6, pp. 17-22, 2014.
[2] C. M. Rath and P. C. Dorrestein, "The bacterial chemical repertoire mediates metabolic exchange within gut microbiomes," Current Opinion in Microbiology, vol. 15, no. 2, pp. 147-154, 2012.

[3] S. Hasegawa, S. Goto, H. Tsuji et al., "Intestinal dysbiosis and lowered serum lipopolysaccharide-binding protein in Parkinson's disease," PLoS One, vol. 10, no. 11, article e0142164, 2015.

[4] A. Keshavarzian, S. J. Green, P. A. Engen et al., "Colonic bacterial composition in Parkinson's disease," Movement Disorders, vol. 30, no. 10, pp. 1351-1360, 2015.

[5] P. Liu, L. Wu, G. Peng et al., "Altered microbiomes distinguish Alzheimer's disease from amnestic mild cognitive impairment and health in a Chinese cohort," Brain, Behavior, and Immunity, vol. 80, pp. 633-643, 2019.

[6] B. Li, Y. He, J. Ma et al., "Mild cognitive impairment has similar alterations as Alzheimer's disease in gut microbiota," Alzheimer's \& Dementia, vol. 15, no. 10, pp. 1357-1366, 2019.

[7] J. P. Haran, S. K. Bhattarai, S. E. Foley et al., "Alzheimer's disease microbiome is associated with dysregulation of the antiinflammatory P-glycoprotein pathway," mBio, vol. 10, no. 3, 2019.

[8] B. Ma, J. Liang, M. Dai et al., "Altered gut microbiota in Chinese children with autism spectrum disorders," Frontiers in Cellular and Infection Microbiology, vol. 9, p. 40, 2019.

[9] I. Cosorich, G. Dalla-Costa, C. Sorini et al., "High frequency of intestinal TH17 cells correlates with microbiota alterations and disease activity in multiple sclerosis," Science Advances, vol. 3, no. 7, article e1700492, 2017.

[10] Y. Fan, H. Wang, X. Liu, J. Zhang, and G. Liu, "Crosstalk between the ketogenic diet and epilepsy: from the perspective of gut microbiota," Mediators of Inflammation, vol. 2019, Article ID 8373060, 9 pages, 2019.

[11] C. Stasi, A. Caserta, C. Nisita et al., "The complex interplay between gastrointestinal and psychiatric symptoms in irritable bowel syndrome: a longitudinal assessment," Journal of Gastroenterology and Hepatology, vol. 34, no. 4, pp. 713-719, 2019.

[12] J. W. Wang, C. H. Kuo, F. C. Kuo et al., "Fecal microbiota transplantation: review and update," Journal of the Formosan Medical Association, vol. 118, Suppl 1, pp. S23-S31, 2019.

[13] M. Grochowska, T. Laskus, and M. Radkowski, "Gut microbiota in neurological disorders," Archivum Immunologiae et Therapiae Experimentalis (Warsz), vol. 67, no. 6, pp. 375-383, 2019. 
[14] C. H. Adler and T. G. Beach, "Neuropathological basis of nonmotor manifestations of Parkinson's disease," Movement Disorders, vol. 31, no. 8, pp. 1114-1119, 2016.

[15] F. Angelucci, K. Cechova, J. Amlerova, and J. Hort, “Antibiotics, gut microbiota, and Alzheimer's disease," Journal of Neuroinflammation, vol. 16, no. 1, p. 108, 2019.

[16] G. R. Lum, C. A. Olson, and E. Y. Hsiao, "Emerging roles for the intestinal microbiome in epilepsy," Neurobiology of Disease, vol. 135, p. 104576, 2020.

[17] A. Peng, X. Qiu, W. Lai et al., "Altered composition of the gut microbiome in patients with drug-resistant epilepsy," Epilepsy Research, vol. 147, pp. 102-107, 2018.

[18] A. Quagliariello, F. Del Chierico, A. Russo et al., "Gut microbiota profiling and gut-brain crosstalk in children affected by pediatric acute-onset neuropsychiatric syndrome and pediatric autoimmune neuropsychiatric disorders associated with streptococcal infections," Frontiers in Microbiology, vol. 9, p. 675, 2018.

[19] M. Fremont, D. Coomans, S. Massart, and K. De Meirleir, "High-throughput 16S rRNA gene sequencing reveals alterations of intestinal microbiota in myalgic encephalomyelitis/chronic fatigue syndrome patients," Anaerobe, vol. 22, pp. 50-56, 2013.

[20] L. Giloteaux, J. K. Goodrich, W. A. Walters, S. M. Levine, R. E. Ley, and M. R. Hanson, "Reduced diversity and altered composition of the gut microbiome in individuals with myalgic encephalomyelitis/chronic fatigue syndrome," Microbiome, vol. 4, no. 1, p. 30, 2016.

[21] D. Missailidis, S. J. Annesley, and P. R. Fisher, "Pathological mechanisms underlying myalgic encephalomyelitis/chronic fatigue syndrome," Diagnostics (Basel), vol. 9, no. 3, 2019.

[22] P. T. Brooks and L. S. Mansfield, "Effects of antibiotic resistance (AR) and microbiota shifts on Campylobacter jejunimediated diseases," Animal Health Research Reviews, vol. 18, no. 2, pp. 99-111, 2017.

[23] S. Mousavi, S. Bereswill, and M. M. Heimesaat, "Novel clinical Campylobacter jejuni infection models based on sensitization of mice to lipooligosaccharide, a major bacterial factor triggering innate immune responses in human campylobacteriosis," Microorganisms, vol. 8, no. 4, 2020.

[24] J. Sun, F. Wang, Z. Ling et al., "Clostridium butyricum attenuates cerebral ischemia/reperfusion injury in diabetic mice via modulation of gut microbiota," Brain Research, vol. 1642, pp. 180-188, 2016.

[25] W. W. Tang, Z. Wang, B. S. Levison et al., "Intestinal microbial metabolism of phosphatidylcholine and cardiovascular risk," The New England Journal of Medicine, vol. 368, no. 17, pp. 1575-1584, 2013.

[26] D. Brenner, A. Hiergeist, C. Adis et al., "The fecal microbiome of ALS patients," Neurobiology of Aging, vol. 61, pp. 132-137, 2018.

[27] X. Fang, X. Wang, S. Yang et al., "Evaluation of the microbial diversity in amyotrophic lateral sclerosis using high-throughput sequencing," Frontiers in Microbiology, vol. 7, p. 1479, 2016.

[28] M. L. Wright, C. Fournier, M. C. Houser, M. Tansey, J. Glass, and V.S. Hertzberg, "Potential role of the gut microbiome in ALS: a systematic review," Biological Research for Nursing, vol. 20, no. 5, pp. 513-521, 2018.

[29] G. Kong, K. A. Lê Cao, L. M. Judd, S. Li, T. Renoir, and A. J. Hannan, "Microbiome profiling reveals gut dysbiosis in a transgenic mouse model of Huntington's disease," Neurobiology of Disease, vol. 135, p. 104268, 2020.
[30] C. I. Wasser, E. C. Mercieca, G. Kong et al., "Gut dysbiosis in Huntington's disease: associations among gut microbiota, cognitive performance and clinical outcomes," Brain communications, vol. 2, no. 2, article fcaa110, 2020.

[31] C. Bundgaard-Nielsen, J. Knudsen, P. D. Leutscher et al., "Gut microbiota profiles of autism spectrum disorder and attention deficit/hyperactivity disorder: a systematic literature review," Gut Microbes, vol. 11, no. 5, pp. 1172-1187, 2020.

[32] D. W. Kang, J. B. Adams, D. M. Coleman et al., "Long-term benefit of microbiota transfer therapy on autism symptoms and gut microbiota," Scientific Reports, vol. 9, no. 1, p. 5821, 2019.

[33] L. Wang, C. T. Christophersen, M. J. Sorich, J. P. Gerber, M. T. Angley, and M. A. Conlon, "Elevated fecal short chain fatty acid and ammonia concentrations in children with autism spectrum disorder," Digestive Diseases and Sciences, vol. 57, no. 8, pp. 2096-2102, 2012.

[34] S. A. Flowers, K. M. Ward, and C. T. Clark, "The gut microbiome in bipolar disorder and pharmacotherapy management," Neuropsychobiology, vol. 79, no. 1, pp. 43-49, 2020.

[35] S. Hu, A. Li, T. Huang et al., "Gut microbiota changes in patients with bipolar depression," Advancement of Science, vol. 6, no. 14, article 1900752, 2019.

[36] T. T. Huang, J. B. Lai, X. Y. Du YL, L. M. Ruan, and S. H. Hu, "Current understanding of gut microbiota in mood disorders: an update of human studies," Frontiers in Genetics, vol. 10, p. 98, 2019.

[37] J. J. Rucklidge and R. Harrison, "Successful treatment of bipolar disorder II and ADHD with a micronutrient formula: a case study," CNS Spectrums, vol. 15, no. 5, pp. 289-295, 2010.

[38] G. B. Fond, J. C. Lagier, S. Honore et al., "Microbiota-orientated treatments for major depression and schizophrenia," Nutrients, vol. 12, no. 4, 2020.

[39] M. Valles-Colomer, G. Falony, Y. Darzi et al., "The neuroactive potential of the human gut microbiota in quality of life and depression," Nature Microbiology, vol. 4, no. 4, pp. 623-632, 2019.

[40] H. Y. Jiang, X. Zhang, Z. H. Yu et al., "Altered gut microbiota profile in patients with generalized anxiety disorder," Journal of Psychiatric Research, vol. 104, pp. 130-136, 2018.

[41] B. Yang, J. Wei, P. Ju, and J. Chen, "Effects of regulating intestinal microbiota on anxiety symptoms: a systematic review," General psychiatry, vol. 32, no. 2, article e100056, 2019.

[42] J. S. Bajaj and A. Khoruts, "Microbiota changes and intestinal microbiota transplantation in liver diseases and cirrhosis," Journal of Hepatology, vol. 72, no. 5, pp. 1003-1027, 2020.

[43] C. M. Sung, Y. F. Lin, K. F. Chen et al., "Predicting clinical outcomes of cirrhosis patients with hepatic encephalopathy from the fecal microbiome," Cellular and Molecular Gastroenterology and Hepatology, vol. 8, no. 2, pp. 301-318, 2019.

[44] B. Lin, Y. Wang, P. Zhang, Y. Yuan, Y. Zhang, and G. Chen, "Gut microbiota regulates neuropathic pain: potential mechanisms and therapeutic strategy," The Journal of Headache and Pain, vol. 21, no. 1, p. 103, 2020.

[45] M. W. Adelman, M. H. Woodworth, C. Langelier et al., "The gut microbiome's role in the development, maintenance, and outcomes of sepsis," Critical Care, vol. 24, no. 1, p. 278, 2020.

[46] T. Cerdo, E. Dieguez, and C. Campoy, "Impact of gut microbiota on neurogenesis and neurological diseases during infancy," Current Opinion in Pharmacology, vol. 50, pp. 33-37, 2020.

[47] C. Gubert, G. Kong, T. Renoir, and A. J. Hannan, "Exercise, diet and stress as modulators of gut microbiota: implications 
for neurodegenerative diseases," Neurobiology of Disease, vol. 134, p. 104621, 2020.

[48] M. M. Pusceddu and J. M. Del Bas, "The role of the gut microbiota in the pathophysiology of mental and neurological disorders," Psychiatric Genetics, vol. 30, no. 4, pp. 87-100, 2020.

[49] H. Huang, H. Xu, Q. Luo et al., "Fecal microbiota transplantation to treat Parkinson's disease with constipation: a case report," Medicine, vol. 98, no. 26, article e16163, 2019.

[50] S. Hazan, "Rapid improvement in Alzheimer's disease symptoms following fecal microbiota transplantation: a case report," The Journal of International Medical Research, vol. 48, no. 6, article 300060520925930, 2020.

[51] T. Borody, S. Leis, J. Campbell, M. Torres, and A. Nowak, "Fecal microbiota transplantation (FMT) in multiple sclerosis (MS): 942," Official journal of the American College of Gastroenterology, vol. 106, 2011.

[52] S. Makkawi, C. Camara-Lemarroy, and L. Metz, "Fecal microbiota transplantation associated with 10 years of stability in a patient with SPMS," Neurology-Neuroimmunology Neuroinflammation, vol. 5, no. 4, article e459, 2018.

[53] Z. He, B. T. Cui, T. Zhang et al., "Fecal microbiota transplantation cured epilepsy in a case with Crohn's disease: the first report," World Journal of Gastroenterology, vol. 23, no. 19, pp. 3565-3568, 2017.

[54] H. Zhao, Y. Shi, X. Luo, L. Peng, Y. Yang, and L. Zou, “The effect of fecal microbiota transplantation on a child with Tourette syndrome," Case Reports in Medicine, vol. 2017, Article ID 6165239, 3 pages, 2017.

[55] X. Ding, F. Zhang, Q. Li, Z. Ting, B. Cui, and P. Li, "Sa1926 selective microbiota transplantation is effective for controlling Tourette's syndrome," Gastroenterology, vol. 156, article S-456, 2019.

[56] T. Borody, A. Nowak, and S. Finlayson, "The GI microbiome and its role in chronic fatigue syndrome: a summary of bacteriotherapy," Journal of the Australasian College of Nutritional and Environmental Medicine, vol. 31, pp. 3-8, 2012.

[57] L. Ward, H. O'Grady, K. Wu, K. Cannon, M. Workentine, and T. Louie, "Combined oral fecal capsules plus fecal enema as treatment of late-onset autism spectrum disorder in children: report of a small case series," Open Forum Infectious Diseases, vol. 3, 2016.

[58] H. Zhao, X. Gao, L. Xi et al., "Mo1667 fecal microbiota transplantation for children with autism spectrum disorder," Gastrointestinal Endoscopy, vol. 89, pp. AB512-AB513, 2019.

[59] R. Hinton, "A case report looking at the effects of faecal microbiota transplantation in a patient with bipolar disorder," The Australian and New Zealand Journal of Psychiatry, vol. 54, no. 6, pp. 649-650, 2020.

[60] T. Cai, X. Shi, L. Z. Yuan, D. Tang, and F. Wang, "Fecal microbiota transplantation in an elderly patient with mental depression," International Psychogeriatrics, vol. 31, no. 10, pp. 1525-1526, 2019.

[61] D. Kao, B. Roach, H. Park et al., "Fecal microbiota transplantation in the management of hepatic encephalopathy," Нераtology, vol. 63, no. 1, pp. 339-340, 2016.

[62] J. S. Bajaj, Z. Kassam, A. Fagan et al., "Fecal microbiota transplant from a rational stool donor improves hepatic encephalopathy: a randomized clinical trial," Hepatology, vol. 66, no. 6, pp. 1727-1738, 2017.

[63] J. S. Bajaj, N. H. Salzman, C. Acharya et al., "Fecal microbial transplant capsules are safe in hepatic encephalopathy: a phase 1, randomized, placebo-controlled trial," Hepatology, vol. 70, no. 5, pp. 1690-1703, 2019.

[64] T. T. Cai, X. L. Ye, H. J. Yong et al., "Fecal microbiota transplantation relieve painful diabetic neuropathy: a case report," Medicine, vol. 97, no. 50, article e13543, 2018.

[65] Q. Li, C. Wang, C. Tang et al., "Therapeutic modulation and reestablishment of the intestinal microbiota with fecal microbiota transplantation resolves sepsis and diarrhea in a patient," The American Journal of Gastroenterology, vol. 109, no. 11, pp. 1832-1834, 2014.

[66] Q. Li, C. Wang, C. Tang et al., "Successful treatment of severe sepsis and diarrhea after vagotomy utilizing fecal microbiota transplantation: a case report," Critical care, vol. 19, 2015.

[67] Y. Wei, J. Yang, J. Wang et al., "Successful treatment with fecal microbiota transplantation in patients with multiple organ dysfunction syndrome and diarrhea following severe sepsis," Critical care, vol. 20, 2016.

[68] S. N. Gopalsamy, A. Sherman, M. H. Woodworth, J. D. Lutgring, and C. S. Kraft, "Fecal microbiota transplant for multidrug-resistant organism decolonization administered during septic shock," Infection Control and Hospital Epidemiology, vol. 39, no. 4, pp. 490-492, 2018.

[69] B. Pakkenberg, A. Moller, H. J. Gundersen, A. Mouritzen Dam, and H. Pakkenberg, "The absolute number of nerve cells in substantia nigra in normal subjects and in patients with Parkinson's disease estimated with an unbiased stereological method," Journal of Neurology, Neurosurgery, and Psychiatry, vol. 54, no. 1, pp. 30-33, 1991.

[70] M. Picillo, R. Palladino, R. Erro et al., “The PRIAMO study: age- and sex-related relationship between prodromal constipation and disease phenotype in early Parkinson's disease," Journal of Neurology, 2020.

[71] M. G. Spillantini, M. L. Schmidt, V. M. Lee, J. Q. Trojanowski, R. Jakes, and M. Goedert, "Alpha-synuclein in Lewy bodies," Nature, vol. 388, no. 6645, pp. 839-840, 1997.

[72] S. Kim, S. H. Kwon, T. I. Kam et al., "Transneuronal propagation of pathologic alpha-synuclein from the gut to the brain models Parkinson's disease," Neuron, vol. 103, no. 4, pp. 627-641, 2019.

[73] F. Scheperjans, V. Aho, P. A. Pereira et al., "Gut microbiota are related to Parkinson's disease and clinical phenotype," Movement Disorders, vol. 30, no. 3, pp. 350-358, 2015.

[74] M. M. Unger, J. Spiegel, K. U. Dillmann et al., "Short chain fatty acids and gut microbiota differ between patients with Parkinson's disease and age-matched controls," Parkinsonism \& Related Disorders, vol. 32, pp. 66-72, 2016.

[75] V. Maini Rekdal, E. N. Bess, J. E. Bisanz, P. J. Turnbaugh, and E. P. Balskus, "Discovery and inhibition of an interspecies gut bacterial pathway for Levodopa metabolism," Science, vol. 364, no. 6445, 2019.

[76] S. P. van Kessel, A. K. Frye, A. O. El-Gendy et al., "Gut bacterial tyrosine decarboxylases restrict levels of levodopa in the treatment of Parkinson's disease," Nature Communications, vol. 10, no. 1, p. 310, 2019.

[77] T. R. Sampson, J. W. Debelius, T. Thron et al., "Gut microbiota regulate motor deficits and neuroinflammation in a model of Parkinson's disease," Cell, vol. 167, no. 6, pp. 1469-1480, 2016.

[78] M. F. Sun, Y. L. Zhu, Z. L. Zhou et al., "Neuroprotective effects of fecal microbiota transplantation on MPTP-induced Parkinson's disease mice: gut microbiota, glial reaction and TLR4/TNF- 
alpha signaling pathway," Brain, Behavior, and Immunity, vol. 70, pp. 48-60, 2018.

[79] S. J. Andrews, B. Fulton-Howard, and A. Goate, "Interpretation of risk loci from genome-wide association studies of Alzheimer's disease," Lancet Neurology, vol. 19, no. 4, pp. 326-335, 2020.

[80] S. S. Dominy, C. Lynch, F. Ermini et al., "Porphyromonas gingivalis in Alzheimer's disease brains: evidence for disease causation and treatment with small-molecule inhibitors," Science Advances, vol. 5, no. 1, article eaau3333, 2019.

[81] D. Pisa, R. Alonso, A. M. Fernandez-Fernandez, A. Rabano, and L. Carrasco, "Polymicrobial infections in brain tissue from Alzheimer's disease patients," Scientific Reports, vol. 7, no. 1, article 5559, 2017.

[82] Y. Zhao, V. Jaber, and W. J. Lukiw, "Secretory products of the human GI tract microbiome and their potential impact on Alzheimer's disease (AD): detection of lipopolysaccharide (LPS) in AD hippocampus," Frontiers in Cellular and Infection Microbiology, vol. 7, p. 318, 2017.

[83] R. Alonso, D. Pisa, A. M. Fernandez-Fernandez, and L. Carrasco, "Infection of fungi and bacteria in brain tissue from elderly persons and patients with Alzheimer's disease," Frontiers in Aging Neuroscience, vol. 10, p. 159, 2018.

[84] D. C. Emery, D. K. Shoemark, T. E. Batstone et al., "16S rRNA next generation sequencing analysis shows bacteria in Alzheimer's post-mortem brain," Frontiers in Aging Neuroscience, vol. 9, p. 195, 2017.

[85] A. Cattaneo, N. Cattane, S. Galluzzi et al., "Association of brain amyloidosis with pro-inflammatory gut bacterial taxa and peripheral inflammation markers in cognitively impaired elderly," Neurobiology of Aging, vol. 49, pp. 60-68, 2017.

[86] R. Maqsood and T. W. Stone, "The gut-brain axis, BDNF, NMDA and CNS disorders," Neurochemical Research, vol. 41, no. 11, pp. 2819-2835, 2016.

[87] C. Marques, M. Meireles, A. Faria, and C. Calhau, "High-fat diet-induced dysbiosis as a cause of neuroinflammation," Biological Psychiatry, vol. 80, no. 1, pp. e3-e4, 2016.

[88] Y. Kobayashi, T. Kinoshita, A. Matsumoto, K. Yoshino, I. Saito, and J. Z. Xiao, "Bifidobacterium breve A1 supplementation improved cognitive decline in older adults with mild cognitive impairment: an open-label, single-arm study," The Journal of Prevention of Alzheimer's Disease, vol. 6, no. 1, pp. 70-75, 2019.

[89] Z. Rezaei Asl, G. Sepehri, and M. Salami, "Probiotic treatment improves the impaired spatial cognitive performance and restores synaptic plasticity in an animal model of Alzheimer's disease," Behavioural Brain Research, vol. 376, p. 112183, 2019.

[90] O. R. Tamtaji, R. Heidari-Soureshjani, N. Mirhosseini et al., "Probiotic and selenium co-supplementation, and the effects on clinical, metabolic and genetic status in Alzheimer's disease: a randomized, double-blind, controlled trial," Clinical Nutrition, vol. 38, no. 6, pp. 2569-2575, 2019.

[91] E. Biagi, L. Nylund, M. Candela et al., "Through ageing, and beyond: gut microbiota and inflammatory status in seniors and centenarians," PLoS One, vol. 5, no. 5, article e10667, 2010.

[92] C. Franceschi, M. Bonafè, S. Valensin et al., "Inflamm-aging. An evolutionary perspective on immunosenescence," Annals of the New York Academy of Sciences, vol. 908, pp. 244-254, 2000 .
[93] T. Harach, N. Marungruang, N. Duthilleul et al., "Erratum: reduction of Abeta amyloid pathology in APPPS1 transgenic mice in the absence of gut microbiota," Scientific Reports, vol. 7, p. 46856, 2017.

[94] H. B. Dodiya, T. Kuntz, S. M. Shaik et al., "Sex-specific effects of microbiome perturbations on cerebral Abeta amyloidosis and microglia phenotypes," The Journal of Experimental Medicine, vol. 216, no. 7, pp. 1542-1560, 2019.

[95] Y. Fujii, T. T. Nguyen, Y. Fujimura et al., "Fecal metabolite of a gnotobiotic mouse transplanted with gut microbiota from a patient with Alzheimer's disease," Bioscience, Biotechnology, and Biochemistry, vol. 83, no. 11, pp. 2144-2152, 2019.

[96] M. S. Kim, Y. Kim, H. Choi et al., "Transfer of a healthy microbiota reduces amyloid and tau pathology in an Alzheimer's disease animal model," Gut, vol. 69, no. 2, pp. 283-294, 2020.

[97] V. S. Chan, "Epigenetics in multiple sclerosis," Advances in Experimental Medicine and Biology, vol. 1253, pp. 309-374, 2020.

[98] E. Cekanaviciute, B. B. Yoo, T. F. Runia et al., "Gut bacteria from multiple sclerosis patients modulate human $\mathrm{T}$ cells and exacerbate symptoms in mouse models," Proceedings of the National Academy of Sciences of the United States of America, vol. 114, no. 40, pp. 10713-10718, 2017.

[99] A. E. Hoban, R. M. Stilling, F. J. Ryan et al., "Regulation of prefrontal cortex myelination by the microbiota," Translational Psychiatry, vol. 6, article e774, 2016.

[100] V. Braniste, M. Al-Asmakh, C. Kowal et al., "The gut microbiota influences blood-brain barrier permeability in mice," Science Translational Medicine, vol. 6, no. 263, article 263ra158, 2014.

[101] J. E. Libbey, J. M. Sanchez, D. J. Doty et al., "Variations in diet cause alterations in microbiota and metabolites that follow changes in disease severity in a multiple sclerosis model," Beneficial microbes, vol. 9, no. 3, pp. 495-513, 2018.

[102] F. Fransen, A. A. van Beek, T. Borghuis et al., "Aged gut microbiota contributes to systemical inflammaging after transfer to germ-free mice," Frontiers in Immunology, vol. 8, p. 1385, 2017.

[103] K. Rea, T. G. Dinan, and J. F. Cryan, “The microbiome: a key regulator of stress and neuroinflammation," Neurobiol Stress, vol. 4, pp. 23-33, 2016.

[104] S. K. Tankou, K. Regev, B. C. Healy et al., "A probiotic modulates the microbiome and immunity in multiple sclerosis," Annals of Neurology, vol. 83, no. 6, pp. 1147-1161, 2018.

[105] J. Chen, N. Chia, K. R. Kalari et al., "Multiple sclerosis patients have a distinct gut microbiota compared to healthy controls," Scientific Reports, vol. 6, p. 28484, 2016.

[106] H. Tremlett, D. W. Fadrosh, A. A. Faruqi et al., "Gut microbiota composition and relapse risk in pediatric MS: a pilot study," Journal of the Neurological Sciences, vol. 363, pp. 153-157, 2016.

[107] A. Mangalam, S. K. Shahi, D. Luckey et al., "Human gutderived commensal bacteria suppress CNS inflammatory and demyelinating disease," Cell Reports, vol. 20, no. 6, pp. 1269-1277, 2017.

[108] O. R. Tamtaji, E. Kouchaki, M. Salami et al., "The effects of probiotic supplementation on gene expression related to inflammation, insulin, and lipids in patients with multiple sclerosis: a randomized, double-blind, placebo-controlled trial," Journal of the American College of Nutrition, vol. 36, no. 8, pp. 660-665, 2017. 
[109] J. Goverman, A. Woods, L. Larson, L. P. Weiner, L. Hood, and D. M. Zaller, "Transgenic mice that express a myelin basic protein-specific $\mathrm{T}$ cell receptor develop spontaneous autoimmunity," Cell, vol. 72, no. 4, pp. 551-560, 1993.

[110] K. Berer, L. A. Gerdes, E. Cekanaviciute et al., "Gut microbiota from multiple sclerosis patients enables spontaneous autoimmune encephalomyelitis in mice," Proceedings of the National Academy of Sciences of the United States of America, vol. 114, no. 40, pp. 10719-10724, 2017.

[111] K. Li, S. Wei, L. Hu et al., "Protection of fecal microbiota transplantation in a mouse model of multiple sclerosis," Mediators of Inflammation, vol. 2020, Article ID 2058272, 13 pages, 2020.

[112] M. Lindefeldt, A. Eng, H. Darban et al., "The ketogenic diet influences taxonomic and functional composition of the gut microbiota in children with severe epilepsy," npj Biofilms and Microbiomes, vol. 5, p. 5, 2019.

[113] G. Xie, Q. Zhou, C. Z. Qiu et al., "Ketogenic diet poses a significant effect on imbalanced gut microbiota in infants with refractory epilepsy," World Journal of Gastroenterology, vol. 23, no. 33, pp. 6164-6171, 2017.

[114] M. Dahlin and S. Prast-Nielsen, "The gut microbiome and epilepsy,” eBioMedicine, vol. 44, pp. 741-746, 2019.

[115] R. K. Sewal, M. Modi, U. N. Saikia, A. Chakrabarti, and B. Medhi, "Increase in seizure susceptibility in sepsis like condition explained by spiking cytokines and altered adhesion molecules level with impaired blood brain barrier integrity in experimental model of rats treated with lipopolysaccharides," Epilepsy Research, vol. 135, pp. 176-186, 2017.

[116] M. Gomez-Eguilaz, J. L. Ramon-Trapero, L. Perez-Martinez, and J. R. Blanco, "The beneficial effect of probiotics as a supplementary treatment in drug-resistant epilepsy: a pilot study," Beneficial Microbes, vol. 9, no. 6, pp. 875-881, 2018.

[117] J. S. Yeom, J. S. Park, Y. S. Kim et al., "Neonatal seizures and white matter injury: role of rotavirus infection and probiotics," Brain and Development, vol. 41, no. 1, pp. 19-28, 2019.

[118] C. A. Olson, H. E. Vuong, J. M. Yano, Q. Y. Liang, D. J. Nusbaum, and E. Y. Hsiao, "The gut microbiota mediates the anti-seizure effects of the ketogenic diet," Cell, vol. 173, no. 7, pp. 1728-1741, 2018.

[119] M. F. Seideman and T. A. Seideman, "A review of the current treatment of Tourette syndrome," Journal of Pediatric Pharmacology and Therapeutics, vol. 25, no. 5, pp. 401-412, 2020.

[120] J. F. Liao, Y. F. Cheng, S. W. Li et al., "Lactobacillus plantarum PS128 ameliorates 2,5-dimethoxy-4-iodoamphetamine-induced tic-like behaviors via its influences on the microbiota-gut-brainaxis," Brain Research Bulletin, vol. 153, pp. 59-73, 2019.

[121] L. A. Snider, L. Lougee, M. Slattery, P. Grant, and S. E. Swedo, "Antibiotic prophylaxis with azithromycin or penicillin for childhood-onset neuropsychiatric disorders," Biological Psychiatry, vol. 57, no. 7, pp. 788-792, 2005.

[122] D. Nagy-Szakal, B. L. Williams, N. Mishra et al., "Fecal metagenomic profiles in subgroups of patients with myalgic encephalomyelitis/chronic fatigue syndrome," Microbiome, vol. 5, no. 1, p. 44, 2017.

[123] J. R. Sheedy, R. E. Wettenhall, D. Scanlon et al., "Increased dlactic acid intestinal bacteria in patients with chronic fatigue syndrome," In Vivo, vol. 23, no. 4, pp. 621-628, 2009.

[124] S. J. Mathew, X. Mao, K. A. Keegan et al., "Ventricular cerebrospinal fluid lactate is increased in chronic fatigue syndrome compared with generalized anxiety disorder: an in vivo 3.0 T (1)H MRS imaging study," NMR in Biomedicine, vol. 22, no. 3, pp. 251-258, 2009.

[125] J. W. Murrough, X. Mao, K. A. Collins et al., "Increased ventricular lactate in chronic fatigue syndrome measured by $1 \mathrm{H}$ MRS imaging at 3.0 T. II: comparison with major depressive disorder," NMR in Biomedicine, vol. 23, no. 6, pp. 643-650, 2010.

[126] D. C. Shungu, N. Weiduschat, J. W. Murrough et al., "Increased ventricular lactate in chronic fatigue syndrome. III. Relationships to cortical glutathione and clinical symptoms implicate oxidative stress in disorder pathophysiology," NMR in Biomedicine, vol. 25, no. 9, pp. 1073-1087, 2012.

[127] B. Storti, M. Vedovello, R. Riva et al., "Posterior reversible encephalopathy and Guillain-Barré syndrome: which came first, the chicken or the egg? A review of literature," Neurological Sciences, vol. 41, no. 12, pp. 3663-3666, 2020.

[128] A. Malik, D. Sharma, J. S. Charles, L. A. Dybas, and L. S. Mansfield, "Contrasting immune responses mediate Campylobacter jejuni-induced colitis and autoimmunity," Mucosal Immunology, vol. 7, no. 4, pp. 802-817, 2014.

[129] J. L. St Charles, J. A. Bell, B. J. Gadsden et al., "Guillain Barre syndrome is induced in non-obese diabetic (NOD) mice following Campylobacter jejuni infection and is exacerbated by antibiotics," Journal of Autoimmunity, vol. 77, pp. 11-38, 2017.

[130] C. W. Ang, J. D. Laman, H. J. Willison et al., "Structure of Campylobacter jejuni lipopolysaccharides determines antiganglioside specificity and clinical features of Guillain-Barre and Miller Fisher patients," Infection and Immunity, vol. 70, no. 3, pp. 1202-1208, 2002.

[131] S. Bereswill, A. Fischer, R. Plickert et al., "Novel murine infection models provide deep insights into the "menage a trois" of Campylobacter jejuni, microbiota and host innate immunity," PLoS One, vol. 6, no. 6, article e20953, 2011.

[132] P. T. Brooks, K. A. Brakel, J. A. Bell et al., “Transplanted human fecal microbiota enhanced Guillain Barre syndrome autoantibody responses after Campylobacter jejuni infection in C57BL/6 mice," Microbiome, vol. 5, no. 1, p. 92, 2017.

[133] P. T. Brooks, J. A. Bell, C. E. Bejcek, A. Malik, and L. S. Mansfield, "An antibiotic depleted microbiome drives severe Campylobacter jejuni-mediated type $1 / 17$ colitis, type 2 autoimmunity and neurologic sequelae in a mouse model," Journal of Neuroimmunology, vol. 337, p. 577048, 2019.

[134] F. H. Karlsson, F. Fåk, I. Nookaew et al., "Symptomatic atherosclerosis is associated with an altered gut metagenome," Nature Communications, vol. 3, p. 1245, 2012.

[135] J. Yin, S. X. Liao, Y. He et al., "Dysbiosis of gut microbiota with reduced trimethylamine- $\mathrm{N}$-oxide level in patients with large-artery atherosclerotic stroke or transient ischemic attack," Journal of the American Heart Association, vol. 4, no. 11, 2015.

[136] O. Koren, A. Spor, J. Felin et al., "Human oral, gut, and plaque microbiota in patients with atherosclerosis," Proceedings of the National Academy of Sciences of the United States of America, vol. 108, Suppl 1, pp. 4592-4598, 2011.

[137] N. Li, X. Wang, C. Sun et al., "Change of intestinal microbiota in cerebral ischemic stroke patients," BMC Microbiology, vol. 19, no. 1, article 191, 2019.

[138] V. Singh, S. Roth, G. Llovera et al., "Microbiota dysbiosis controls the neuroinflammatory response after stroke," The Journal of Neuroscience, vol. 36, no. 28, pp. 7428-7440, 2016. 
[139] R. Chen, P. Wu, Z. Cai et al., "Puerariae Lobatae Radix with chuanxiong Rhizoma for treatment of cerebral ischemic stroke by remodeling gut microbiota to regulate the braingut barriers," The Journal of Nutritional Biochemistry, vol. 65, pp. 101-114, 2019.

[140] H. S. Nam, J. Ha, D. Ji et al., "Elevation of the gut microbiota metabolite trimethylamine $\mathrm{N}$-oxide predicts stroke outcome," Journal of stroke, vol. 21, no. 3, pp. 350-352, 2019.

[141] S. Yang, X. Li, F. Yang et al., "Gut microbiota-dependent marker TMAO in promoting cardiovascular disease: inflammation mechanism, clinical prognostic, and potential as a therapeutic target," Frontiers in Pharmacology, vol. 10, p. 1360, 2019.

[142] G. H. Xia, C. You, X. X. Gao et al., "Stroke dysbiosis index (SDI) in gut microbiome are associated with brain injury and prognosis of stroke," Frontiers in Neurology, vol. 10, p. 397, 2019.

[143] R. Hergesheimer, D. Lanznaster, P. Vourc'h et al., “Advances in disease-modifying pharmacotherapies for the treatment of amyotrophic lateral sclerosis," Expert Opinion on Pharmacotherapy, vol. 21, no. 9, pp. 1103-1110, 2020.

[144] M. R. Minter, R. Hinterleitner, M. Meisel et al., "Antibioticinduced perturbations in microbial diversity during postnatal development alters amyloid pathology in an aged APPSWE/PS1DeltaE9 murine model of Alzheimer's disease," Scientific Reports, vol. 7, no. 1, article 10411, 2017.

[145] J. Mandrioli, A. Amedei, G. Cammarota et al., "FETR-ALS study protocol: a randomized clinical trial of fecal microbiota transplantation in amyotrophic lateral sclerosis," Frontiers in Neurology, vol. 10, p. 1021, 2019.

[146] H. D. Rosas, G. Doros, S. Bhasin et al., “A systems-level "misunderstanding": the plasma metabolome in Huntington's disease," Annals of Clinical Translational Neurology, vol. 2, no. 7, pp. 756-768, 2015.

[147] S. Cheng, B. Han, M. Ding et al., "Identifying psychiatric disorder-associated gut microbiota using microbiota-related gene set enrichment analysis," Briefings in Bioinformatics, vol. 21, no. 3, pp. 1016-1022, 2020.

[148] Z. Yang, J. Li, X. Gui et al., "Updated review of research on the gut microbiota and their relation to depression in animals and human beings," Molecular Psychiatry, vol. 25, no. 11, pp. 2759-2772, 2020.

[149] R. Bhandari, J. K. Paliwal, and A. Kuhad, "Neuropsychopathology of autism spectrum disorder: complex interplay of genetic, epigenetic, and environmental factors," Advances in Neurobiology, vol. 24, pp. 97-141, 2020.

[150] M. De Angelis, R. Francavilla, M. Piccolo, A. De Giacomo, and M. Gobbetti, "Autism spectrum disorders and intestinal microbiota," Gut Microbes, vol. 6, no. 3, pp. 207-213, 2015.

[151] N. Principi and S. Esposito, "Gut microbiota and central nervous system development," The Journal of Infection, vol. 73, no. 6, pp. 536-546, 2016.

[152] J. Qin, R. Li, J. Raes et al., "A human gut microbial gene catalogue established by metagenomic sequencing," Nature, vol. 464, no. 7285, pp. 59-65, 2010.

[153] L. Desbonnet, G. Clarke, F. Shanahan, T. G. Dinan, and J. F. Cryan, "Microbiota is essential for social development in the mouse," Molecular Psychiatry, vol. 19, no. 2, pp. 146-148, 2014.

[154] A. E. Golnik and M. Ireland, "Complementary alternative medicine for children with autism: a physician survey," Jour- nal of Autism and Developmental Disorders, vol. 39, no. 7, pp. 996-1005, 2009.

[155] A. Partty, M. Kalliomaki, P. Wacklin, S. Salminen, and E. Isolauri, "A possible link between early probiotic intervention and the risk of neuropsychiatric disorders later in childhood: a randomized trial," Pediatric Research, vol. 77, no. 6, pp. 823-828, 2015.

[156] M. Urbanska, D. Gieruszczak-Bialek, and H. Szajewska, "Systematic review with meta-analysis: Lactobacillus reuteri DSM 17938 for diarrhoeal diseases in children," Alimentary Pharmacology \& Therapeutics, vol. 43, no. 10, pp. 1025-1034, 2016.

[157] S. A. Buffington, G. V. Di Prisco, T. A. Auchtung, N. J. Ajami, J. F. Petrosino, and M. Costa-Mattioli, "Microbial reconstitution reverses maternal diet-induced social and synaptic deficits in offspring," Cell, vol. 165, no. 7, pp. 1762-1775, 2016.

[158] G. Sharon, N. J. Cruz, D. W. Kang et al., "Human gut microbiota from autism spectrum disorder promote behavioral symptoms in mice," Cell, vol. 177, no. 6, pp. 1600-1618, 2019.

[159] K. Aabed, R. S. Bhat, N. Moubayed et al., "Ameliorative effect of probiotics (Lactobacillus paracaseii and Protexin(R)) and prebiotics (propolis and bee pollen) on clindamycin and propionic acid-induced oxidative stress and altered gut microbiota in a rodent model of autism," Cellular and Molecular Biology (Noisy-le-Grand, France), vol. 65, no. 1, pp. 1-7, 2019.

[160] A. Painold, S. Mörkl, K. Kashofer et al., "A step ahead: exploring the gut microbiota in inpatients with bipolar disorder during a depressive episode," Bipolar Disorders, vol. 21, no. 1, pp. 40-49, 2019.

[161] E. Z. Reininghaus, L. C. Wetzlmair, F. T. Fellendorf et al., "The impact of probiotic supplements on cognitive parameters in euthymic individuals with bipolar disorder: a pilot study," Neuropsychobiology, vol. 79, pp. 63-70, 2018.

[162] C. A. Simpson, O. S. Schwartz, and J. G. Simmons, "The human gut microbiota and depression: widely reviewed, yet poorly understood," Journal of Affective Disorders, vol. 274, pp. 73-75, 2020.

[163] Y. Zhang, R. Huang, M. Cheng et al., "Gut microbiota from NLRP3-deficient mice ameliorates depressive-like behaviors by regulating astrocyte dysfunction via circHIPK2," Microbiome, vol. 7, no. 1, p. 116, 2019.

[164] J. R. Kelly, Y. Borre, C. O'Brien et al., “Transferring the blues: depression-associated gut microbiota induces neurobehavioural changes in the rat," Journal of Psychiatric Research, vol. 82, pp. 109-118, 2016.

[165] S. Noonan, M. Zaveri, E. Macaninch, and K. Martyn, "Food \&amp;amp; mood: a review of supplementary prebiotic and probiotic interventions in the treatment of anxiety and depression in adults," BMJ Nutrition, Prevention \&amp;amp; Health, no. article bmjnph-2019-000053, 2020.

[166] P. Xie, "Alterating the gut microbiome by microbiota transplantation from depressed patients into germ-free mice results in depressive-like behaviors through a pathway mediated by the host's metabolism," European Neuropsychopharmacology, vol. 27, pp. S478-S479, 2017.

[167] L. M. Frankiensztajn, E. Elliott, and O. Koren, “The microbiota and the hypothalamus-pituitary-adrenocortical (HPA) axis, implications for anxiety and stress disorders," Current Opinion in Neurobiology, vol. 62, pp. 76-82, 2020.

[168] I. Lurie, Y. X. Yang, K. Haynes, R. Mamtani, and B. Boursi, "Antibiotic exposure and the risk for depression, anxiety, or 
psychosis: a nested case-control study," The Journal of Clinical Psychiatry, vol. 76, no. 11, pp. 1522-1528, 2015.

[169] J. A. Bravo, P. Forsythe, M. V. Chew et al., "Ingestion of Lactobacillus strain regulates emotional behavior and central GABA receptor expression in a mouse via the vagus nerve," Proceedings of the National Academy of Sciences of the United States of America, vol. 108, no. 38, pp. 16050-16055, 2011.

[170] G. De Palma, M. D. Lynch, J. Lu et al., "Transplantation of fecal microbiota from patients with irritable bowel syndrome alters gut function and behavior in recipient mice," Science Translational Medicine, vol. 9, no. 379, 2017.

[171] Z. Zhang, H. Zhai, J. Geng et al., "Large-scale survey of gut microbiota associated with MHE via $16 \mathrm{~S}$ rRNA-based pyrosequencing," The American Journal of Gastroenterology, vol. 108, no. 10, pp. 1601-1611, 2013.

[172] T. Kawaguchi, F. Suzuki, M. Imamura et al., "Rifaximin-altered gut microbiota components associated with liver/neuropsychological functions in patients with hepatic encephalopathy: an exploratory data analysis of phase II/III clinical trials," Hepatology Research, vol. 49, no. 4, pp. 404-418, 2019.

[173] D. C. Rosenberger, V. Blechschmidt, H. Timmerman, A. Wolff, and R. D. Treede, "Challenges of neuropathic pain: focus on diabetic neuropathy," Journal of Neural Transmission (Vienna), vol. 127, no. 4, pp. 589-624, 2020.

[174] P. Jamshidi, S. Hasanzadeh, A. Tahvildari et al., "Is there any association between gut microbiota and type 1 diabetes? A systematic review," Gut pathogens, vol. 11, p. 49, 2019.

[175] F. Bäckhed, H. Ding, T. Wang et al., "The gut microbiota as an environmental factor that regulates fat storage," Proceedings of the National Academy of Sciences of the United States of America, vol. 101, no. 44, pp. 15718-15723, 2004.

[176] A. Vrieze, E. Van Nood, F. Holleman et al., "Transfer of intestinal microbiota from lean donors increases insulin sensitivity in individuals with metabolic syndrome," Gastroenterology, vol. 143, no. 4, pp. 913-916, 2012.

[177] R. Guo, L. H. Chen, C. Xing, and T. Liu, "Pain regulation by gut microbiota: molecular mechanisms and therapeutic potential," British Journal of Anaesthesia, vol. 123, no. 5, pp. 637-654, 2019.

[178] S. Shen, G. Lim, Z. You et al., "Gut microbiota is critical for the induction of chemotherapy-induced pain," Nature Neuroscience, vol. 20, no. 9, pp. 1213-1216, 2017.

[179] V. Castelli, P. Palumbo, M. d'Angelo et al., "Probiotic DSF counteracts chemotherapy induced neuropathic pain," Oncotarget, vol. 9, no. 46, pp. 27998-28008, 2018.

[180] J. Huang, C. Zhang, J. Wang, Q. Guo, and W. Zou, “Oral Lactobacillus reuteri LR06 or Bifidobacterium BL5b supplement do not produce analgesic effects on neuropathic and inflammatory pain in rats," Brain and Behavior: A Cognitive Neuroscience Perspective, vol. 9, no. 4, article e01260, 2019.

[181] A. Mazeraud, C. Righy, E. Bouchereau, S. Benghanem, F. A. Bozza, and T. Sharshar, "Septic-associated encephalopathy: a comprehensive review," Neurotherapeutics, vol. 17, no. 2, pp. 392-403, 2020.

[182] P. F. Czempik, M. P. Pluta, and L. J. Krzych, "Sepsis-associated brain dysfunction: a review of current literature," International Journal of Environmental Research and Public Health, vol. 17, no. 16, 2020.

[183] H. Li, J. P. Limenitakis, V. Greiff et al., "Mucosal or systemic microbiota exposures shape the B cell repertoire," Nature, vol. 584, no. 7820, pp. 274-278, 2020.
[184] S. Li, J. Lv, J. Li et al., "Intestinal microbiota impact sepsis associated encephalopathy via the vagus nerve," Neuroscience Letters, vol. 662, pp. 98-104, 2018.

[185] K. Y. Ebino, H. Amao, T. Suwa, Y. Kuwabara, T. R. Saito, and K. W. Takahashi, "Coprophagy in the germfree mouse," Jikken Dobutsu, vol. 36, no. 1, pp. 33-37, 1987.

[186] H. T. Chen, H. L. Huang, H. M. Xu et al., "Fecal microbiota transplantation ameliorates active ulcerative colitis," Experimental and Therapeutic Medicine, vol. 19, no. 4, pp. 26502660, 2020.

[187] W. Gao, A. P. Salzwedel, A. L. Carlson et al., "Gut microbiome and brain functional connectivity in infants-a preliminary study focusing on the amygdala," Psychopharmacology, vol. 236, no. 5, pp. 1641-1651, 2019.

[188] F. M. Zhang and Y. F. Liu, "Evidence and decision of the choice of delivery way in washed microbiota transplantation," Zhonghua Wei Chang Wai Ke Za Zhi, vol. 23, no. Z1, pp. 45-47, 2020.

[189] T. Zhang, G. Lu, Z. Zhao et al., "Washed microbiota transplantation vs. manual fecal microbiota transplantation: clinical findings, animal studies and in vitro screening," Protein \& Cell, vol. 11, no. 4, pp. 251-266, 2020. 